\title{
EL OBISPADO DE PALENCIA DESDE SUS ORÍGENES HASTA SU DEFINITIVA RESTAURACIÓN EN EL SIGLO XI*
}

\author{
POR \\ ÁNGEl VACA L LORENZo \\ Facultad de Geografia e Historia. Salamanca
}

\begin{abstract}
RESUMEN
En este trabajo de Historia se pretende aclarar la constitución del obispado de Palencia desde sus oscuros origenes hasta su definitiva restauración en la primera mitad del siglo XI. Tal objetivo se persigue a lo largo de tres apartados que se corresponden con otras tantas etapas históricas: la primitiva creación del obispado en época visigoda, los múltiples intentos fallidos por instaurar una diócesis en las recién repobladas tierras palentinas $\mathrm{y}$, finalmente, la definitiva restauración de la sede episcopal por obra de los reyes Sancho III de Navarra, Bermudo III de León y Femando I de Castilla y León.
\end{abstract}

\begin{abstract}
In this Historical essay, it is intended to clarify the constitution of the bishopric of Palencia from its obscure origins until the final restoration in the first half of the 11th. century. Such an aim is sougnt along three parts which correspond
\end{abstract}

* Este artículo es fruto de una investigación de más amplio calado titulada «Geografía eclesiástica de la diócesis de Pajencia en tiempo del obispo don Vasco (1343-1353) y financiada por la DGICYT (PS 94-0122). Agradezco la amigable colaboración del prof. Izquierdo Misiego en la confección de los mapas que se insertan.

Enviado a la imprenta, tengo conocimiento de la publicación de MARTinez DIEZ, G., «Los cinco diplomas relativos a la restauración de la diócesis palentina por Sancho el Mayom, Publicaciones de la Institución «Tello Téllez de Meneses», 68 (1997) 161-189, cuyas aportaciones en nada contradicen a las aqui realizadas.

Actas del I Congreso de Historia de la Iglesia y el Mundo Hispánico

Hispania Sacra, 52 (2000) 
with many more historical stages: the primitive creation of the bishopric in the Visogoth era, the numerous failed attempts to set up a diocese in the recently repopulated lands of Palencia and, finnally, the last restoration of the episcopal seat by the kings Sancho III of Navarra, Bermudo III of Leon and Fernando I of Castilla and Leon.

«Con dificultad puede correr la pluma en la materia de este primer libro, pues (...) lo que de Palencia sucedió, desde su fundación, hasta que la desolaron los Árabes, son materias obscuras»; así inicia Fernández del Pulgar su Historia secular y eclesiástica de la ciudad de Palencia ${ }^{1}$. Lo mismo cabe decir de la implantación del Crístianismo en Palencia, como de la posterior creación de la diócesis episcopal: sus origenes son inciertos e inseguros, rodeados de ficciones y fabulaciones transmitidas por falsos cronicones y dudosas historias. En afirmación de Flórez, la ignorancia que tenemos sobre la fundación de Palencia abraza también al origen de la Cristiandad, por no saberse cosa cierta acerca de los ministros determinados que empezaron a predicar alli $^{2}$. Desde luego, hoy se sabe que ni al prefecto palentino Cayo Carpo, ni al apóstol Santiago, ni al obispo San Néstor ni al francés San Frontón, discípulo de San Pedro, cabe imputarles autoría alguna en la fundación de la iglesia y diócesis palentinas.

De todas formas, se suele afirmar que, una vez conquistada por Roma, Palencia y el antiguo territorio de los vacceos «se engrandeció con la predicación del cristianismo y el establecimiento de la diócesis» ${ }^{3}$ y que gozó de sede episcopal desde los primeros tiempos de la implantación de la organización eclesiástica en Hispania ${ }^{4}$. La ubicación de la ciudad de Pallantia en la red viaria romana, en concreto en la vía que desde Tarragona se dirigía a Astorga, así como el hecho de no existir en la región de los vacceos otra ciudad importante,

I P. Fernández del Puloar, Historia secular y eclesiástica de la ciudad de Palencia. Madrid, 1679 , libro I, p. 1 .

2 E. FLóREZ, España sagrada. Madrid 1860, tomo VIII, p. 5.

${ }^{3}$ H. YABEN, "Origen y restauración del Obispado de Palencia», Semana «pro ecclesia et patria». Palencia 1934, p. 135. Es posible que el Cristianismo hubiese penetrado en estas tierras a finales del siglo II o principios del siguiente, ya que por esta época se documenta la existencia del obispado de León-Astorga, vid. D. Mansilla ReoYo, Geografía eclesiástica de España. Estudio histórico-geográfico de las diócesis. Roma, Publicaciones del Instituto Español de Historia Eclesiástica, 1994, tomo I, pp. 85 y ss. Efectivamente, en el año 254 el obispo Basílides era el jefe de la comunidad cristiana de Astorga-León, vid. M. C. DiAZ Y DiAZ, «En tomo a los origenes del Cristianismo hispánico», Las raices de Esparia. Madrid, Instituto Espanfol de Antropologfa Aplicada, 1967, p. 435.

4 «El origen de la Silla episcopal es incierto, aunque remoto, y probablemente anterior a los tiempos de Constantino, al siglo IVm, en expresión de F. SImón y NiETo, Los Antiguos Campos Góticos. Madrid 1895, p. 21, not. 1 .

Actas del I Congreso de Historia de la Iglesia y el Mundo Hispánico Hispania Sacra, $52(2000)$ 
ciertamente lleva a presuponer su temprana evangelización y elección como una de las posibles sedes episcopales de Hispania; ahora bien, la propagación y florecimiento del Cristianismo en esta parte del Imperio comenzó por la regiones más romanizadas, principalmente por la provincia de la Bética, en conexión directa con el norte de Africa y dificilmente cabe imaginar una organización administrativa eclesiástica que englobara toda la Península antes del siglo IV. Desde luego, en la relación nominal de los diecinueve obispos y de los veinticuatro presbíteros asistentes al primer concilio hispano reunido en Elvira (Granada) en torno a los afios 300-302 no consta ni el prelado ni la sede episcopal de Palencia ${ }^{5}$. Además, la tesis actual dominante sostiene que la cristianización del mundo rural en la Península comenzó en la segunda mitad del siglo IV, que en los albores del siglo $\mathrm{V}$ la evangelización campesina seguía siendo desigual e incompleta, existiendo aún regiones por cristianizar, como el territorio cántabro, y que el movimiento priscilianista y la difusión de las iglesias rurales desempeñaron un importante papel en la cristianización de las regiones del noroeste peninsular, donde el grado de urbanización alcanzado era muy escaso ${ }^{6}$

\section{El obispado de Palencia EN La ÉPOCA VISIGOdA: SUS PRIMERos PRELADOS}

Aunque cabe cierta posibilidad de que el primitivo origen del obispado palentino se remonte a la época del Bajo Imperio Romano, en concreto al siglo IV, hasta la llegada de los pueblos germánicos a la Península $\mathrm{y}$, más explícitamente hasta la ocupación visigoda de la Meseta no se poseen pruebas documentales claras y seguras de su existencia, o cuando menos de sus primeros prelados conocidos? ${ }^{7}$. Desde luego, carece del suficiente poder de convicción la aseveración de Flórez de que en el siglo $\mathrm{V}$ ocupó la sede episcopal palentina PASTOR, obispo de origen gallego, de quien se sabe que en el 433 fue ordenado juntamente con Siagrio «in conventu Lucensi» contra la voluntad de Agrestio, obispo de Lugo y priscilianista o por lo menos simpatizante. De este supuesto

${ }^{5}$ Vid. D. Mansilla Reovo, ob. cit., tomo I, pp. 91 y ss. La relación de los asistentes en J. Vives, Concilios visigóticos e hispano-romanos. Barcelona-Madrid, CSIC, 1963, p. 1; y G. MARTtNEZ DIEZ y F. Rodrf́uez, Colección Canónica Hispana. Madrid, CSIC, 1984, vol, IV, pp. 239-4l.

6 Vid. M. I. Lorno Garcia, «La difusión del Cristianismo en los medios rurales de la Península Ibérica a fines del Imperio romanow, Stvdia Historica. $H^{a}$ Antigua, IV-V (1986-87) 195-204.

7 Asumo plenamente la afirmación de que «en realidad la conformación de una estructura eclesiástica jerarquizada en el ámbito de la Meseta debe asociarse con el proceso de asentamiento de los godos, y su consolidación con la conversión de los mismos al catolicismon, expresada por P. C. Díaz, «La diócesis de Osma en la Antigledad", Actas del X Curso Universitario de Verano. Universidad de Santa Catalina (1550-1841). El Burgo de Osma (Soria) 1998, p. 217. 
obispo palentino se aventura que fue uno de los dos prelados que el rey Teodorico se llevó prisionero a Orleans en el 457, cuando como aliado de los romanos penetró en Hispania para luchar contra los suevos que habían anexionado parte de las provincias Tarraconense, Cartaginense y Lusitana, destruyendo las ciudades de Astorga y Palencia ${ }^{8}$; en su destierro, el improbable obispo palentino Pastor escribiría un Libellum in modum symboli contra los priscilianistas'. El hecho de que este obispo fuera ordenado en el convento jurídico de Lugo y no en el de Clunia, como bien afirma Celine Martín, «invalida su hipotética relación con Palencia» ${ }^{10}$. Y aún es menos probable considerar como obispo de Palencia a PEDRO que en las actas del concilio de Agde (Francia) de 506 firma como «episcopus de Palatio", sede desconocida tanto en las Galias como en Hispania y que algunos han pretendido identificar con Pallantia, justificando su presencia en la Galia Narbonense por seguir la corte del rey Alarico ${ }^{11}$.

La llegada de los pueblos germánicos y, en especial la intervención del rey godo Teodorico contra los suevos que habían ampliado grandemente su primitiva zona de asentamiento en la parte exterior de la provincia Galaica, pudo perturbar gravemente la vida de esta región y, en concreto su vida religiosa hasta el extremo de favorecer la supervivencia de las doctrinas priscilianistas durante bastante tiempo ${ }^{12}$, hasta las predicaciones de los dos Toribios, el santo obispo

8 «Palentina civitas simili quo Asturica per gothos perit exitio» testifica Hidacio. Fueron Teodorico y sus godos y no los suevos, como afirma Simón y Nieto, los responsables del saqueo de la ciudad de Palencia y del cautiverio del entonces hipotético obispo palentino Pastor, vid. F. Simón Y NIETo, ob. cit., p. 19, E. Flórez, ob. cit., tomo VII, p. 12 y ss. y P. Fernández del Pulgar, ob. cit., libro I, pp. 329-334. De todas formas, las hostilidades fronterizas que a lo largo de los siglos V y VI mantuvieron visigodos y suevos, no sólo afectó gravemente a la ciudad de Palencia, sino también a todo el poblamiento occidental del obispado, lo mismo que las incursiones cántabras incidirian negativamente en el poblamiento de la parte septentrional, vid. J. GonZÁLEZ, «Cuestiones de repoblación en tierras palentinasy, Palencia en la Historia. Palencia, Diputación Provincial, 1982, p. 50.

9 Vid. D. Mansilla Reoyo, ob. cit., tomo I, pp.173-174.

${ }^{10} \mathrm{C}$. MARTiN, «Las cartas de Montano y la autonomía episcopal de la Hispania septentrional en el siglo VI》, Hispania Antigva, XXII (1998) 414.

"Vid. H. YABEN, ob. cit., pp. 139-143 y E. FLóREZ, ob. cit., tomo VIII, pp. 12-18. M. Rouche, L'Aquitaine des wisigoths ano arabes, 418-781. Naissance d'une région. Paris, Editions de l'Ecole des Hautes Etudes en Sciences Sociales, 1979, p. 47 presenta un mapa con la procedencia de los obispos que participaron o estuvieron representados en dicho concilio.

12 «La atomización del poder habría implicado, por las dificultades de comunicación, por la inseguridad o por los impedimentos impuestos por los suevos en Gallaecia, una pérdida de disciplina eclesiástica, la ausencia de criterios doctrinales uniformes, y habria generado, en conjunto, unas condiciones idóneas para la proliferación de las herejías, y en especial del priscilianismo.

Las fuentes no permiten valorar el alcance de esta situación, en concreto de la difusión del priscilianismo, en nuestra área de referencia [valle del Duero]. Pero la carta que el metropolitano de Toledo, Montano, dirige en tomo al 527 al clero de Palencia, denuncia la tolerancia que hacia al priscilianismo se tiene en la zona, lo que sin duda no es un fenómeno reciente», en P. C. DíaZ, «La ocupación germá-

Actas del I Congreso de Historia de la Iglesia y el Mundo Hispánico Hispania Sacra, $52(2000)$ 
de Astorga y el monje-sacerdote palentino, y la pretendida destrucción de la ciudad de Palencia como consecuencia de la inducida inundación del río Carrión por el santo, que aún hoy se recuerda en la anual procesión-romería a la ermita del Otero.

En este contexto, se sabe que hacia el año 530 Montano, metropolitano de la iglesia de Toledo que presidió el concilio II de dicha ciudad, remitió dos cartas: una al clero de Palencia y otra a Toribio, monje-sacerdote enviado a la ciudad del Carrión para corregir las actuaciones anticanónicas del clero diocesano y luchar contra las pervivencias priscilianistas ${ }^{13}$. De sus respectivos contenidos ${ }^{14}$ se deduce, entre otras cuestiones, que el metropolitano de Toledo tenía jurisdicción sobre el territorio palentino, que la ciudad de Palencia era sede de una diócesis sufragánea dotada de obispo propio, si bien en aquel momento carecía de él por circunstancias especiales ${ }^{15}$, así como la futura provisión de un nuevo obispo que pusiese fin a la vacante entonces existente.

¿Se produjo la deseada consagración episcopal por parte del metropolitano toledano? Cabe la posibilidad, pero desde luego es imposible demostrarla por carecer de la oportuna información. Lo único que parece cierto es que la diócesis palentina ya existía y tenía un reconocimiento pleno, aunque carecía de obispo católico al producirse la conversión del rey Recaredo al credo niceno, cuando menos nada se indica sobre la duplicidad de obispos en esta sede, del antiguo

nica del valle del Duero: un ensayo interpretativon, Hispania Antiqua, XVIII (1994) 465. Acerca de la vitalidad alcanzada por el movimiento priscilianista en las regiones noroccidentales remito al artículo ya citado de M. 1. LóRNG GARCiA, ob. cit., principalmente pp. 195-202.

${ }^{13}$ Ambas hállanse insertas en E. FLóreZ, ob. cit, tomo V, Apéndice III, pp. 409-421; J. Vives, ob. cit, pp. 46-52; y G. MARTineZ DieZ y F. RoDriguez, ob. cit., vol. IV, pp. 356-66.

${ }_{14}$ La primera, dirigida «a los sefiores queridisimos hermanos e hijos del territorio palentinon, de tono amenazador, uacusa a los presbiteros palentinos de consagrar elfos mismos el crisma de invitar a obispos ajenos para la consagración de nuevas basílicas, y de seguir honrando al hereje Prisciliano. La segunda carta empieza por atabar a Toribio por su acción contra el priscilianismo, pero a continuación repite los reproches antes enumerados, y finalmente, mencionando un priuilegium concedido por su coepiscopo a los obispos de Carpetania, le amenaza con recurrir a las autoridades seglares si deja que se perpetúen tales abusos», en C. MARTíN, ob. cit., pp. 404-405 y también en A. BARBERo DE AGULLERA, "Las divisiones eclesiásticas y la relaciones entre la lglesia y el Estado en la España de los siglos VI y VIl», La Historia en el contexto de las ciencias humanas y sociales. Homenaje a Marcelo Vigil Pascual. Salamanca, Ediciones Universidad de Salamanca, 1989, pp. 174-75.

${ }^{15}$ Según Flórez, el año 527 tuvo lugar en Palencia una elección y consagración de obispo hecha contra los cánones, por lo que fue anulada por el propio Montano, E. FLóREZ, ob. cit., tomo V, pp. 18 y ss. Mientras que Celine Martín piensa que efectivamente el obispo de Palencia habia sido ordenado de forma irregular, por lo que «habría sido destituido de su cargo por los obispos de Carpetania, quizás en un concilio cuyas actas se perdieron. Se le concederían unos municipios [Segovia, Buitrago y Coca] para su sustento, y él a cambio redactaría un documento (...) en el que reconocería la mengua de sus poderes", quedando convertido en un coepiscopo, C. MARTIN, ob. cit., p. 421. 
titular cristiano y del nuevo prelado convertido al catolicismo. Así, en el año 589 en que tuvo lugar el III concilio de Toledo, se documenta la pública y solemne profesión de fe católica del obispo arriano MAURILA o MURLA ${ }^{16}$, quien desde mucho antes de la celebración de este concilio, tal vez nombrado por Leovigildo, regía únicamente para la fracción racial germánica, los gothi, la diócesis arriana de Palencia y en ella continuó, ahora ya como pastor de toda la comunidad católica e hispanogoda, hasta como mínimo el año 607. Desde entonces, Palencia aparece como una de las diócesis más importantes de la Hispania visigoda ubicada en la provincia de la Cartaginense y de la que se conocen otros cuatro prelados anteriores a la llegada de los árabes:

El primero es CONANCIO, asistente al IV, V y VI concilios de Toledo y a quien algunos le confieren la santidad. Sucedió a Murila y rigió el obispado palentino durante más de treinta años, ya que fue consagrado a fines del reinado de Witerico, posiblemente en el 607, y su muerte acaeció antes de la del rey Chintila (23 diciembre 639) ${ }^{17}$. Fundó en Palencia una escuela catedralicia para la formación de clérigos y en ella tuvo como alumno a San Fructuoso, el abadobispo de Dumio y luego metropolitano de Braga. Compuso algunas melodías musicales y escribió un libro de oraciones sobre los salmos. Fue uno de los quince prelados de la provincia Cartaginense que el 23 de octubre del 610 declararon y reconocieron a la sede de Toledo como única metrópoli eclesiástica de dicha provincia; acuerdo episcopal sobre la dignidad primacial de Toledo confirmado poco tiempo después por el rey Gundemaro y veintiséis obispos más. Su biografia fue escrita por San Ildefonso.

El segundo responde al nombre de ASCARIO, quien asistió al VIII concilio de Toledo (653) y aún seguía rigiendo la diócesis palentina en el $661^{18}$. Influyó en Recesvinto para la construcción de la iglesia de San Juan de Baños y posiblemente también de la cripta de San Antolín de Palencia. Su consagración debió producirse poco después de la celebración del VII concilio de Toledo (646), al

\footnotetext{
16 «Murila in Christi nomine episcopus anathematizans haeresi Arrianae dogmata superius damnata, fidem hanc nostram (sanctam) catholican, quam in eccl. cath. (ecclesia catholica) veniens credidi, manu mea (de) toto corde ss. (subscripsi)», en J. VIVEs, ob. cit., p. 136 y en G. MARTíneZ DiEZ y F. RODRigUEZ, ob. cit., vol. V, p. 95.

${ }^{17}$ «Conantius post Murilanem, ecclesiae Palentinae sedem adeptus est, (...) vixit in pontificatu amplius triginta annis, dignus habitus fuit ab ultimo tempore Witterici per tempora Gundemari, Sisebuti, Suinthilanis, Sisenandi, et Chintilae», en L. A. Garcia Moreno, Prosopografía del reino visigodo de Toledo. Salamanca, Universidad de Salamanca, 1974, p. 140. La asistencia de este obispo a los distintos concilios toledanos, en J. VIVES, $a b$. cit., pp. 222, 230 y 246; y en G. MARTiNEZ DiEZ y F. RODRiGUEZ, ob. cit., vol. V, pp. 262, 288 y 331.

${ }^{18}$ L. A. Garcia Moreno, ob. cit., p. 140. J. Vives, ob. cit., p. 287; y G. MARTiNez Diez y F. RodRiGUEZ, ob. cit., vol. IV, p. 443.
} 
que no asistió ningún obispo palentino, por lo que cabe suponer que por entonces estaba vacante la silla episcopal.

El tercero es CONCORDIO, que participó personalmente en los concilios XI (675), XII (681), XIII (683) y XV (688) de Toledo ${ }^{19}$ y representado por el diácono Gravidio en el XIV $(684)^{20}$, por lo que su consagración debió suceder algún tiempo antes del XI concilio, pero, casi con toda probabilidad bastante tiempo después de la muerte de Ascario, por lo que hay que suponer la existencia de un prelado «indocumentado» entre ambos (¿acaso Droganio?) o un largo periodo de vacancia en la sede palentina.

Y el cuarto y último plenamente documentado es BoRoALDO o BASUALDO, que suscribió las actas del concilio XVI $(693)^{21}$ y, como su firma no aparece en las actas de los concilios XVII (694) y XVIII (701), es posible que ya no ocupase la silla palentina en el momento de la llegada de los árabes.

Dificil asignar un territorio más o menos preciso a la diócesis palentina en tiempos de los visigodos. De hecho, como afirma Sánchez-Albornoz, «las divisiones eclesiásticas hispanovisigodas constituyen todavía una cuestión sin resolver ${ }^{22}$, en parte porque el principal documento para poder reconstruir la geografia eclesiástica visigoda en España, usualmente conocido como «División» o "Hitación de Wamba»" ${ }^{23}$, se ha demostrado no ser auténtico, sino un producto de fines del siglo XI o principios del XII, cuando tienen lugar los numerosos conflictos interdiocesanos para la determinación exacta y precisa de los límites de los obispados creados a medida que avanzaba la frontera cristianomusulmana hacia el Sur ${ }^{24}$.

19 F. VIVES, ob. cit., pp. 368, 401, 432 y 471.

20 «Gravidius diaconus, vicarius Concordi episcopi Palentini», Ibidem, p. 448.

21 Ibidem, p. 519.

22 C. SANCHEZ ALborNoz, «Fuentes para el estudio de las divisiones eclesiásticas visigodas", Investigaciones y documentos sobre las Instituciones Hispanas. Santiago de Chile, Editorial Juridica de Chile, 1970, p. 66. Quien, al finalizar dicho articulo, afirma que con la información de las fuentes hoy disponibles no «puede irse muy lejos en la fijación de los límites de las sedes episcopales de la época visigoda. Mientras nuevos datos no vengan a despejar la incógnita de la Hitación y a ayudar la tarea de los investigadores, tendremos que resigmamos a ignorar la geografia diocesana española anterior a la reconquistas (p. 107).

23 Una supuesta delimitación de las sedes episcopales hispanas realizada por el monarca visigodo Wamba (672-80) en un concilio de Toledo, sefialando en cada uno de los obispados los cuatro mojones o puntos extremos de sus límites, que se citan de dos a dos, sin cerrar el circuito entre ellos. La delimitación se hace por metropolis, empezando por la toledana y sin que se le asigne a ella límites, sino a las diócesis sufragáneas. Por lo general, el extremo de cada sede citado como segundo término se repite como el primero de la sede siguiente.

24 E. Flórez atribuyó su autoría a don Pelayo, el gran falsario obispo de Oviedo, mientras que Vázquez de Parga fija la fecha probable de esta falsificación cuando el metropolitano de Toledo, don Ber- 
Se sabe que la organización territorial eclesiástica peninsular de la etapa visigoda se basó en la tradición administrativa romana del Bajo Imperio, fundamentalmente en la ordenación de Diocleciano del año 297, sin despreciar la influencia real que en dicha administración debieron ejercer las diversas agrupaciones de pueblos o tribus indígenas existentes en la Península Ibérica en el momento de la conquista romana ${ }^{25}$. Las seis provincias eclesiásticas hispanas que aparecen claramente definidas en las Etimologías de San Isidoro, coincidieron en sus límites con las antiguas provincias romanas, salvo los lógicos reajustes producidos por la propia presencia y dinámica histórica de los visigodos en la Península desde el siglo V al VIII, junto con los otros pueblos: suevos y bizantinos ${ }^{26}$. De hecho, el cambio en el dominio del territorio por un determinado pueblo en ocasiones suponía también el cambio en las demarcaciones de las provincias eclesiásticas, pasando algunas diócesis de una a otra provincia. Tal fluctuación se hizo más evidente en la región noroeste ocupada por los suevos desde mediados del siglo V hasta fines del VI. Durante dicha dominación, Galicia, cuyos límites provinciales estaban delimitados por el mar, el Duero y el Cea-Esla, se expandió hacia el Sur por debajo del Mondego y hacia el Este penetrando en las provincias Tarraconense y Cartaginense. Pero, una vez derrotados los suevos por los visigodos de Teodorico, fueron restituidos los antiguos límites de la provincia Galaica con la Lusitana, mientras que en el Este se produjo un recorte de su territorio al pasar Cantabria a la circunscripción provincial de la Tarraconense. Fue entonces cuando posiblemente surgió en territorio cántabro la sede episcopal de Amaya, ciudad romana de Cantabria situada a 65 kilómetros de Burgos y cerca de Alar del Rey ${ }^{27}$, así como el obispado de Oca.

\footnotetext{
nardo, pretendió incorporar a su metrópoli la sede episcopal de Burgos (1097), en concreto afirma que «fue forjado en el obispado de Osma o en Toledo en un periodo de tiempo comprendido entre el Concilio de Husillos (1088) y los afios 1107-8, en que Pascual II alude al «scriptura illud uetus quos Oxomensis Episcopus habere se dicib), en L. VAZQUEZ DE PARGA, La división de Wamba. Contribución al estudio de la Historia y Geografia eclesiásticas de la Edad Media españolas. Madrid, CSIC, 1943, p. 92. Pero, incluso aunque se tratara de un original, poco es lo que aporta a la deteminación precisa del perimetro diocesano palentino, ya que únicamente define cuatro puntos: Palentia teneat de Mambella usque Caltom de Ualbona usque Fortosam. Hoy día las únicas fuentes válidas para el conocimiento de la organización territorial de las diócesis hispanovisigodas son las actas de los concilios de Toledo y las listas de las sedes episcopales existentes en diversos códices altomedievales, pero todas ellas poseen informaciones extremadamente parcas sobre este aspecto.

${ }^{25}$ Sobre este tema remito al Capitulo I: "Antigusas divisiones político-administrativas de Espafia» de D. MANSILA ReOYo, $o b$. cit., I, pp. 23 y ss.

${ }_{26}$ Sobre la influencia de estos pueblos en la organización de la administración territorial eclesiástica, véase el ya citado artículo de A. BARBero de AGUILERA, ob. cit, pp. 169-89.

27 D. MANSIlla ReOYo, ob. cit., I, p. 49.
} 
MAPA 1

La diócesis de Palencia en tiempos de los visigodos

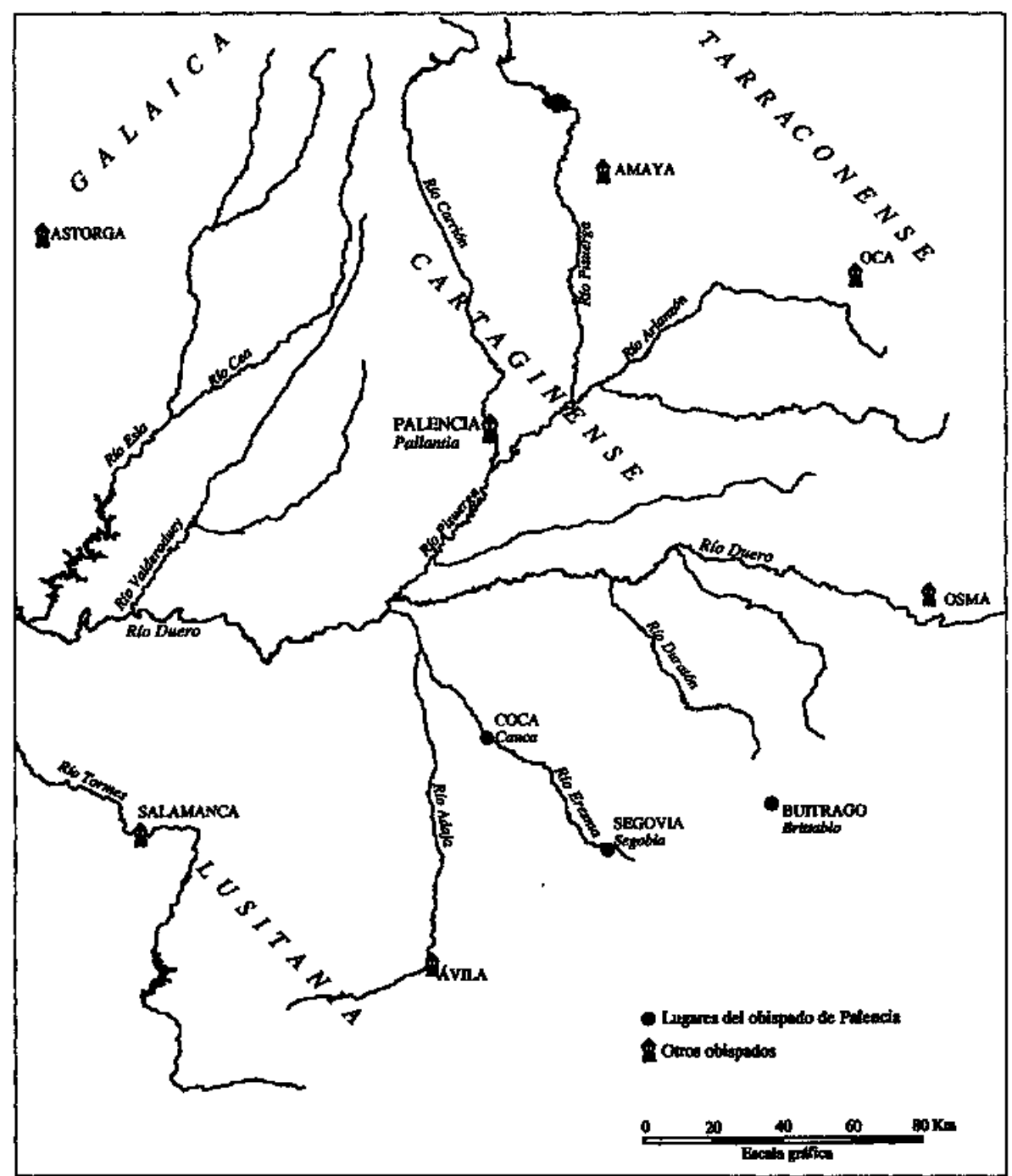

Actas del I Congreso de Historia de la Iglesia y el Mundo Hispánico

Hispania Sacra, 52 (2000) 
Si las provincias eclesiásticas calcaron su circunscripción de la organización civil, también las diócesis, sin duda las demarcaciones territoriales eclesiásticas por excelencia, debieron proceder de la tradición administrativa romana, en este caso de los municipios; el territorio de cada diócesis correspondía con los límites de cada civitas, con su urbs y su territorium, aunque desgraciadamente no se conserva ningún documento que indique con precisión los límites de cada una de las numerosas diócesis, unas ochenta, que existían en la Hispania visigoda. Las fuentes documentales se reducen simplemente a enumerar las diócesis y su pertenencia a cada una de las seis provincias, sin ofrecer más detalles geográficos.

La diócesis palentina pertenecía a la provincia Cartaginense, en cuyo extremo noroccidental se hallaba ubicada a modo de cuffa entre las provincias Galaica y Tarraconense. Limitaba al Oeste con la provincia Galaica y la diócesis de Astorga, al Nordeste con la provincia Tarraconense y las diócesis de Amaya y Oca, al Este con la diócesis de Osma, al Sur con la de Segovia, ambas pertenecientes a la provincia Cartaginense, y al Suroeste con la provincia Lusitana y las diócesis de Salamanca y Avila (Vid. Mapa 1). Precisar más sus límites es entrar en el terreno de las hipótesis. Parece muy probable que la línea divisoria con la provincia Galaica se situara a lo largo de los rios Cea hasta el Esla y Valderaduey hasta su desembocadura en el Duero. Probable también la delimitación con los cántabros que al Norte ocupaban la parte montañosa, la raya divisoria pudo partir de Villapadierna o Cistierna, no lejos del nacimiento del río Esla, y seguir la zona montañosa de la cordillera Cantábrica hasta alcanzar el río Pisuerga a la altura de Alar del Rey. El río Pisuerga, la frontera más antigua del condado de Castilla en expresión del poema de Fernán González ${ }^{28}$, separaba a la diócesis de Palencia de la de Oca, perteneciente a la provincia Tarraconese. Fijar los otros límites de la diócesis palentina que la separaban de Osma, Segovia (territorio de los arevacos), Avila o Salamanca (betones), resulta una tarea hoy día infructuosa; se sabe que su jurisdicción traspasaba el río Duero, pues Plinio le atribuye la ciudad de Coca, llegando hasta las estribaciones de la sierra de Guadarrama e incluyendo los territorios de Segovia, Buitrago y el ya citado de Coca. Sin embargo, en el año 527 el metropolitano de Toledo, Montano, concedió de por vida estos últimos territorios al obispo palentino consagrado anticanónicamente, a fin de resolver dicha situación ${ }^{29}$; tales territorios, cedidos

\footnotetext{
28 «Estonçe era Castielia un pequeño rincón, /era de castellanos Montes d’Oca mojón, /e de la otra parte Fituero (Itero del Castillo) el fondón, /moros tenién Caraço en aquella sazón's, en Poema de Fernán González (ed. H. Salvador Martínez). Madrid, Espasa Calpe, 1991, p. 87 (estrof. 171).

29 «Et certe municipia, id est Segobiam, Brittablo et Caucam eidem non quidem rationabiliter, sed pro nominis dignitate, concessimus; ne collata benedictio persona vagante, vilescerebs en E. FĹ́REZ, $o b$. cit., tomo V, Apéndice III, p. 416; J. VIVEs, ob. cit., p. 51 ; y G. MARTínez Díez y F. RoDriGuEz, ob. cit., vol. IV, p. 365.
} 
en principio transitoriamente, nunca más volvieron a formar parte de la diócesis de Palencia, sino que desgajados constituyeron la base nuclear para la fundación de la diócesis de Segovia; de hecho ya en el concilio III de Toledo (589) suscriben sus actas Proculus Segobiensis ecclesiae episcopus y Petrus Segobiensis ecclesiae episcopus ${ }^{30}$.

Al producirse la invasión musulmana, el obispado palentino desaparece ${ }^{31} y$ sobre él se cierne un silencio de más de tres siglos, sólo roto por fugaces y en algunos casos dudosas detonaciones documentales en los siglos IX y X. Los historiadores todavía se interrogan sobre lo sucedido en el valle del Duero y, en concreto en su vertiente septentrional, desde la irrupción árabe hasta finales del siglo IX, en que Alfonso III incorporó este territorio al dominio político del reino asturiano al mandar populare las desertas ab antiquis ciudades de Cemore, Septimancas et Donnas vel omnes Campi Gotorum y encomendar ta puebla de Toro a su hijo García ${ }^{32}$.

Para unos, siguiendo la clásica teoría álbornociana, esta región se habría convertido en un verdadero desierto carente de población, aun cuando dicho proceso habría arrancado con mucha anterioridad, desde el siglo III, acentuándose en la propia época visigoda y culminando a mediados del siglo VIII. Tal despoblación sería la consecuencia de una serie de hechos, entre los que destacan: la corriente migratoria que hacia el norte peninsular suscitó la invasión muslim de 711; la rebelión de los bereberes contra los árabes en el segundo tercio del siglo VIII y la consiguiente marcha de los primeros, asentados en la Meseta superior, hacia el Sur; las campañas de saqueo y destrucción realizadas por el rey Alfonso I, quien con objeto de incrementar los pobladores del reino asturiano se llevo consigo a los cristianos de la Meseta, al tiempo que convertía ésta en una especie de foso defensivo interpuesto entre los reinos asturiano y musulmán; o los años de hambre, de 748 a 753, padecidos en el interior de la

${ }^{30}$ En J. Vives, ob. cit, pp. 137 y 138. El primer suscriptor, Próculo, sería el obispo católico, mientras que Pedro sería el que habia abandonado el credo arriano.

${ }^{31}$ De esta forma tan cruda se describe la desaparición de la antigua sede palentina en el privilegio del rey Fernando I de 29 diciembre 1059: «Sed dolo serpentis antiqui et pro magnis sceleribus populi, introierunt in eam agareni et funditus destruxerunt Sanctam Ecclesiam et neci dederunt eius pulcherrimam prolem. In qua destructione ecclesiarum totius Yspanie, naufragium pertulit ciuitas et ecclesia sedis palentine, que CCC annis et eo amplius extitit sine episcopali regimine et quasi uiduata maritali coniunctione, luculento amictu et sectis genis, sedit in longa desolatione. Et ubi antea fiebat sacrificium pro salute animarum, totum dedecoratur a stercore aulum et a poluta sue ismaelitarum. Et quale prius studium colebatur honoris et quoadusque tendunt eius diocesis termini, tunc totum traditum est obliuionì, en T. ABajo Martin, Documentación de la catedral de Palencia (1035-1247). Burgos 1986, doc. 9.

${ }_{32}$ J. PÉREZ DE URBEL, Sampiro. Su crónica y la monarquía leonesa en el siglo X. Madrid 1952, p. 305. 
Península Ibérica. Es entonces cuando el obispado palentino habría desaparecido tanto desde el punto de vista administrativo como desde el punto de vista de territorio habitado.

Para otros, siguiendo la también ya clásica teoría de Menéndez Pidal, la irrupción musulmana no habría supuesto la desaparición integral de los pobladores hispanogodos del valle del Duero; al contrario, la mayoría de ellos habrían capitulado y pactado con los nuevos invasores y habrían continuado residiendo en sus lugares habituales, encontrándolos allí la marea cristiana. Sólo aquellos gothi, comprometidos con la causa del derrotado Rodrigo, se habrían visto obligados a huir de sus tierras y a refugiarse en las montañas septentrionales. Pero, al igual que los partidarios de la teoria albornociana, los seguidores de ésta también postulan la desaparición de toda organización administrativa en estos territorios durienses, permaneciendo sin un control político efectivo por ninguno de los dos pueblos peninsulares, el musulmán y el cristiano.

En ambos posicionamientos existe, pues, plena coincidencia en afirmar el desmantelamiento de toda organización político-administrativa en este territorio y, por ende de la propia organización eclesiástica existente con anterioridad a la invasión musulmana. De todas formas se conocen ciertas pruebas documentales de la persistencia de algún obispo palentino, en concreto de un tal ABUNDANCIO, un siglo después de la llegada de los sarracenos a la Península ${ }^{33}$. Ahora bien, estas pruebas, aunque presentan numerosas y justificadas dudas de autenticidad, parecen apuntar a que este obispo, en el improbable caso de haber existido con ese título ${ }^{34}$, no residía en la ciudad de Palencia ni ejercía un poder religioso sobre una circunscripción territorial concreta, sino en el reino de Asturias, $o$ en el monasterio de Valcavado, a la vana espera de volver a recuperar la diócesis palentina. Por lo que hay que negar cualquier posibilidad de continuidad, ni siquiera formal, del obispado visigodo de Palencia en el siglo IX. Todos los indicios documentales apuntan, pues, a su desaparición en el siglo VIII, interrumpiéndose las sucesiones episcopales.

\footnotetext{
${ }^{33}$ "Arruinada la ciudad de Palencia por los sarracenos, su obispo se retiró a Asturias, donde vivieron también los que le sucedieron en el título hasta el reinado de D. Alonso el Casto, en que lo era Abundancio, según el concilio Ovetense celebrado en el afio 811. En los tiempos siguientes no suena ya obispo palentinom, en E. FLóREZ, ob. cit., tomo VIII, p. 32. En este concilio, de controvertida autenticidad, se pretendió someter a la silla ovetense las diócesis recién creadas y aun las por crear, entre las cuales se encontraba la de Palencia; sin duda, se trata de una de las muchas actas falsas o, al menos, adulteradas fabricadas por el conocido falsario el obispo don Pelayo (1101-1129), en su afán de eludir las pretensiones del metropolitano toledano, Bernardo (1086-1124), de someter la iglesia de Oviedo a Toledo.

${ }^{34}$ Lo que hoy nadie sostiene y en su día negó con rotundidad P. Fernández. del PUlgar, ob. cit, libro I, pp. 675 y ss.
}

Actas del I Congreso de Historia de la Iglesia y el Mundo Hispánico Hispania Sacra, 52 (2000) 
Desde luego, con la invasión musulmana y sucesos inmediatamente posteriores no sólo habría desaparecido el obispado palentino, sino también la propia ciudad de Palencia como tal; por lo menos es lo que se infiere de su no relación expresa en la larga lista de ciuitates saqueadas por el rey Alfonso I a mediados del siglo VIII ${ }^{35}$, ni en la más reducida de las ciudades de Zamora, Simancas, Dueñas y Toro, mandadas populare por el rey Alfonso III a finales del IX. Todo parece indicar que para la ciudad de Palencia la invasión musulmana supuso el aldabonazo final de su total despoblación o en una proporción tan importante como para perder su condición urbana ${ }^{36}$. De todas formas, ya en la primera mitad del siglo X Palencia estaba poblada y en su segunda mitad habia adquirido cierta importancia como centro administrativo de un territorio en el que se hallaba ubicada, entre otras, la villa que Manni Ovécoz habiéndola heredado de sus padres y abuelos donaba a la iglesia de León en $977^{37}$.

\section{LA MULTIPLICIDAD DE INTENTOS FALLIDOS POR INSTAURAR UNA DIÓCESIS EN TIERRAS PALENTINAS}

A lo largo de la segunda mitad del siglo IX y primera del X, aprovechando las dificultades internas de al-Andalus, se produce la gran expansión de la monarquía astur. En el reinado de Ordoño I (850-866) se repueblan Astorga y León, así como Tuy y Amaya; en el de Alfonso III (866-910) se fija el tramo de la frontera central o leonesa en el río Duero con la ocupación de Zamora, Toro,

35 «Id est. Lucum, Tudem, Portugalem, Angiam, bracaram metropolitanam, Uiseo, flauias, Letesma, Salamantica, Numantia qui nunc uocatur Zamora, Abela, Astorica, Legionem, Septemmanca, Saldania, Amaja, Secobia, Oxoma, Septempuplica, Arganza, Clunia, Mabe, Auco, Miranda Reuendeca Carbonarica Abilica Cinasaria et Alesanzo», en M. Gómez MORENo, "Las primeras crónicas de la reconquista), $B R A H, 100$ (1932) 615-616.

36 Hay autores, como Becerro de Bengoa o Simón y Nieto que, apoyándose en un dudoso alegato de Antonio Ruiz Navanuel, afirman que la invasión musulmana únicamente destruyó una parte de la ciudad de Palencia, la situada en la orilla izquierda del rio Carrión, pero no la otra parte («Allende el ríon), donde permanecieron hasta tiempos avanzados varias iglesias parroquiales, ermitas y eremitorios, y que fueron los condes de Villafruela, D. Froyla Odoariz y su esposa doña Flámula de Guzmán, quienes, reinando Ordoño II, reconstruyeron la ciudad en el año 921. Vid. R. BECERRo DE BENGOA, El libro de Palencia. Palencia 1874, pp. 85-86 y F. Simón Y NiETo, ob. cit., pp. 29-30. Tal alegato fue rebatido contundentemente por los anotadores de la Silva Palentina, D. Matías Vielva y D. Ramón Revilla, en $O b$. cit., pp. $65-68$ y nota 19 .

37 «et est ipsa uilla in territorio Palencie, ripa riuulo Karrione», en G. DEL SER QUIJANO, Documentación de la catedral de León. (Siglos $D X y X$ ). Salamanca, Ediciones Universidad de Salamanca, 1981, doc. 36 y E. SAEZ y C. SÁEZ, Colección documental del archivo de la catedral de León (775-1230). II (953-985). León, Centro de Estudios e Investigación «San Isidoro», 1990, doc. 451.

Actas del I Congreso de Historia de la Iglesia y el Mundo Hispánico Hispania Sacra, 52 (2000) 
Simancas y Dueñas; en el de García I (910-914) es el tramo oriental o castellano el que se extiende hasta dicho río con la anexión de Roa, Osma, Clunia y San Esteban de Gormaz; y, finalmente, en el de Ramiro II (931-950) se consiguen incorporar las Extremaduras leonesa y castellana, mediante la repoblación de Salamanca, Ledesma, Ribas, Baños y Alhándega en el valle del Tormes, y de Sepúlveda en las estribaciones de Somosierra. El restablecimiento del poder político andalusí en la persona del omeya Abd al-Rahman III y el resquebrajamiento del reino leonés por las crisis dinásticas y tendencias particularistas surgidas a la muerte de Ramiro II provocaron la paralización del avance cristiano al Sur y, más tarde, el retroceso de su frontera meridional al río Duero.

Coincidiendo con esta expansión territorial del reino astur desde la cordillera Cantábrica al Sistema Central, sus reyes procedieron a la implantación de la organización eclesiástica mediante el encuadramiento del territorio en diócesis. Ordofio I creó el obispado de León antes de 860 y restauró el de Astorga hacia los años $852-4^{38}$; sin embargo, fue a partir del reinado de Alfonso III cuando se produjo el mayor impulso de la reorganización eclesiástica con la constitución de los obispados de Coimbra, Lamego, Oporto, Mondofiedo, Zamora, Viseo y Álava.

Dificil determinar a qué obispado pertenecía el territorio palentino en estos tiempos. Parece ser que en un primer momento entra a formar parte de los obispados de Oviedo y León; de hecho, el 20 de enero de 905, el rey Alfonso IIl y su mujer, la reina Jimena, en unión de sus hijos, de omnibus ecclesiis que sunt de terminis Astorice, usque in flumen Carrione, in loco ubi nascitur, et usque se iungit in Pisorga, et usque ad Zamora, medietatem concedimus omnium ecclesiarum, parroquiarum ouetensi ecclesia aliam medietatem legionensi ecclesie. Palentiam etiam concedimus cum omni sua diocesi ${ }^{39}$. Donación que vuelve a

38 La «primera noticia cierta de la sede no aparece hasta el 26 de mayo del affo 860, en que Ordotio I concede al obispo Frunimio I las iglesias de Santa Eulalia, Santa María, cerca de los ríos Lena y Aller en Asturias. Es probable que León tuviera ya prelado antes de esa fecha, y si tenemos en cuenta que la repoblación se hizo al mismo tiempo que en Astorga, no habria dificultad en adelantar algunos afos la fecha de la fundación del obispado de León. Por lo que a Astorga se refiere, sabemos que su sede se restauró hacia el af́o 852-854, cuando el obispo Indisclo y el conde Gatón procedentes del Bier$z o$, se empeffan a fondo en la doble tarea de la repoblación y de la restauración religiosa. No hay dificultad en aceptar también esa fecha para León, ya que es muy probable se llevara a cabo conjuntamente la decisión y desde luego en el reinado de Ordono I», en D. MaNsilla ReOYo, ob. cit., tomo II, pp. 37-38. Para Quintana Prieto la fecha de la restauración del obispado de Astorga se centraría en los afios 852-3, llegando a creer que «la primavera del primero de estos dos años sea la fecha exacta que buscamos», en A. QuinTANa PRIETo, «El obispado de Astorga en el siglo IX. Restauración y episcopologio», Hispania Sacta, 18 (1965) 171.

${ }^{39}$ Edit. en A. C. FloRIANo, Diplomática espathola del período astur. Estudio de las fuentes documentales del reino de Asturias (718-910). Oviedo, Instituto de Estudios Asturianos, 1949-51, tomo II, doc. 175 . 
repetirse en otras dos ocasiones: el 11 de abril de 906, un plagio literal del primer documento ${ }^{40}$, y el 10 de agosto de 908 , prácticamente una repetición de los anteriores, «parafraseando el documento del 906, disfrazando levemente las frases, recalcando las donaciones y acentuando el tono ofercional, como con un empeño mal disimulado de superar la solemnidad del documento de $905 »^{41}$. Ahora bien, la consideración de falsa que se otorga a dicha donación impide corroborar tal posibilidad ${ }^{42}$.

Años después, el territorio palentino parece pertenecer al obispado de León en exclusiva, ya que el 17 de abril de 916 se fecha el documento en que Ordono II dona a la iglesia de León diversos comisos, villas e iglesias: en Campis Gotorum, hec sunt: in Uerrot Zancos, quod est Castrum Uiride cum uillulis suis: Carlon et Quintanella, Ratores, Romeses, Sancta Maria. In termino de Monte Molion, Capellas cum uillulis suis Bouata et Pozolos, Ualle Auria, ecclesia Sancte Marie de Auarca, así como en un amplio territorio que delimita in primis per terminum de Astoriga; et inde per terminum de Zamora, quod est Castrum Gunsaluo iben Muza; et per terminum de Tauro; et terminum Septemmancas, quod est Castrum de Aeiza Gutierriz in Ornisa; terminum de Domnas; terminum de Capezone; terminum de Modra; et inde per Acseua de Castro Uiuester usque in Castro Uiride; Bretauellos duos, Ciuicos duos, Tarego, Balneos, Palentina, Monteson, Sancta Maria de Carrion, Saldania, Sancto Romano de Pennas cum uillulis suis, Ceruaria et Castelion, et Petras Nigras cum uillulis suis simul et Leuana; et inde per pennas de illos portos usque in termino iam dicto de Astorig $a^{43}$. Sin embargo, sus editores consideran este documento de segura falsedad, realizado en el siglo XII, cuando tuvieron lugar las mayores disputas sobre límites episcopales y, por ende, las mayores falsificaciones ${ }^{44}$.

40 Edit. Ibídem, doc. 187, G. DEL Ser QuJano, ob. cit, doc. 5 y E. SAeZ, Colección documental del archivo de la catedral de León (775-1230). I (775-952). León, Cent. de Est. e Invest. «San Isidoro», 1987, doc. 20.

4 Edit. en A. C. Floriano, ob. cil., doc. 192.

42 Los tres diplomas han sido catalogados por Floriano Cumbref̂o como falsedades diplomáticas, realizadas en el siglo XII por el obispo Pelayo el primero y por alumnos adelantados los otros dos. Y de la misma opinión son F. J. FerNáNDEz CONDE, El libro de los testamentos de la catedral de Oviedo. Roma, Instituto Español de Historia Eclesiástica, 1971, pp. 159-69, G. DEL SER QUiJANO, ob. cit., p. 27 y E. SÁEZ, ob. cit., p. 32.

43 Edit. en G. Del Ser Quijano, ob. cit., doc. 7 y E. SÁeZ, ob. cit., doc. 39.

4 «Nos encontranos ante un documento de segura falsedad, por las razones siguientes: la desaforada donación que contiene; el insólito estilo de sus partes formularias; y la aparición de confirmantes que son de épocas posteriores: la reina Urraca, mujer de Ordoño III; los obispos Arias, de Mondonedo; Juan, de Zamora, y Salvato, de Salamanca, y algunos de los magnates que lo suscribeny, en E. SÁEZ, ob. cit., p. 59. 
Efectivamente, más bien parece una copia literal ampliada de un diploma posterior, 17 de abril de 955; en él consta que Ordoño III ofrece a Santa María y al obispo don Gonzalo la sede de León, con sus términos, que establece de termino de Astorice; et inde per termino de Zamora, quod est Castro de Gundisaluo iben Muza; et inde per termino de Tauro et termino de Septimanca, quod est Castro de Aueiza Gutterriz; in Ornisia Angurellos et Naua Bona cum suas uillas $a b$ integritate, siue et Tridigarios, Domnas cum omnes suas uillas ab integro; Cabezon et suas uillas, Modora et suas uillas; in Agoseua de Castro Uiuester quousque in Castro Uiride, Bretauellos duos, Ciuicos duos, Tarego, Balneos, Uilla Maurelli cum suas uillas ab integro, Palentina cum suas uillas; in Monteson cum suas uillas, Sancta Maria in Carrion cum suas uillas, Saldania et Sancto Romano, siue et Boardo, Zeione, Reangulo, et Eone quod est termino de Leuana; et omnia, quod infra ipsos terminos concludet, ab integro usque in Legione. Asimismo le concede las villas quod auio nostro iam in testamento posuerat; id sunt: Bouata et Fonte de Kapellas ${ }^{45}$. Documento este último que también ofrece dudas sobre su autenticidad; si Sánchez-Albornoz ${ }^{46}$ o Ser Quijano ${ }^{47}$ suponen, con bastante seguridad, su autenticidad, para E. Sáez y C. Sáez resulta, con ligeras diferencias, un doble del falso de Ordoño II de $17 \mathrm{de}$ abril de 916, es decir, dos diplomas falsos salidos de una mano muy posterior a la época ${ }^{48}$; opinión, esta última que también comparte Mansilla Reoyo ${ }^{49}$.

Es precisamente en esta época, en que tuvo lugar la significativa victoria de Simancas en 939 y la creación del condado de Monzón por el rey Ramiro II en tierras palentinas, cuando suceden los primeros y diversos intentos, ciertamente dubitativos y a la postre todos ellos fallidos, de implantar una organización eclesiástica propia en este territorio, mediante la restauración del extinto obispado palentino de época visigoda o la erección de otros nuevos.

El primer intento de restablecer la diócesis palentina se sitúa antes de mediados del siglo $\mathrm{X}$ en la persona del obispo don JULIÁN y centrado en la ciudad de Palencia. Desde luego se carece, si es que alguna vez existió, del acta real fundacional; como tal obispado siempre aparece indisolublemente unido a su prelado, don Julián.

Poco es lo que de este obispo se conoce; en sus listados no suelen incluirlo los episcopologios palentinos y prácticamente había pasado desapercibido hasta

\footnotetext{
45 Edit. en G. DEL Ser QuUANo, ob. cit., doc. 28 y E. SÁEz y C. SAEZ, ob. cit., doc. 287.

46 C. SANCHEZ-AlBorNOZ, «El obispado de Simancas», Miscelánea de Estudios Históricos. León, Centro de Estudios e Investigación «San Isidoro», 1970, p. 400.

${ }^{47}$ G. DEL SER QuJano, ob. cit., p. 29.

48 E. SÁEZ Y C. SAEZ, ob. cit., p. 49.

49 D. Mansilla ReOYo, ob. cit, tomo II, pp. 41 y ss.
} 
el estudio del profesor Martínez Díez ${ }^{50}$. Su primera aparición documentada, como Julianus, Dei gratia sedis pallentinae episcopus, data del 11 de abril de 940; en ella confirma, junto con los obispos de Oviedo, Zamora, León, Astorga, Viseo, Lugo, Orense, Compostela y Coimbra, la donación de la iglesia de San Martín del valle de Parada y Cebraria de Astorga realizada por el rey Ramiro II al monasterio berciano de Santiago de Peñalba ${ }^{51}$. Cuatro años después, en el 944, vuelve de nuevo a aparecer documentado como palentine sedis episcopus y como episcopus Palentia sedis, en ambos casos confirmando, en primer lugar el 11 de noviembre de 944, la donación del rey Ramiro II al monasterio de Sahagún de la villa de Pozolos ${ }^{52}$ y, en el otro caso once días después, una ratificación del conde de Castilla, Asur Fernández, de la venta de Santa Eulalia de Agés al monasterio de San Salvador de Loberuela ${ }^{53}$.

Estas son las tres menciones expresas e indiscutiblemente documentadas sobre la figura de este obispo palentino. De todas formas, el citado profesor Martínez Diez cree posible su origen andaluz; en concreto se trataría del último obispo sevillano ${ }^{54}$, a quien, emigrado de su diócesis hispalense, se le encomendaría el nuevo obispado palentino, erigido entre los limites de la diócesis leonesa y el río Pisuerga. Asimismo, el citado profesor cree posible que en el año 931 el obispo Julián ya rigiera la diócesis palentina desde el lugar de Castro Vivester, despoblado actual a orillas del Esgueva ${ }^{55}$, para pasar a regirla con posterioridad, probablemente el año 937 y con certeza el 940, desde la propia ciudad de Palencia hasta al menos el año 944 y posiblemente hasta más allá del $950^{56}$.

50 G. MaRTh́NeZ Díz, «El obispado de Palencia en el siglo X», «Liber Amicorum». Prof. D. Ignacio de la Concha. Oviedo, Publicaciones de la Universidad, 1986, pp. 339-348.

51 Edit. en A. QUINTANA PRIETo, Peñalba (estudio histórico sobre el monasterio berciano de San. tiago de Perialba). León 1963, doc. I, p. 120.

52 Edit. en J. M. Minguez FERNÁNDEZ, Colección diplomática del monasterio de Sahagún. (Siglos $L X y X$ ). León, Centro de Estudios e Investigación «San Isidoro», 1976, doc. 93, p. 124. Los obispos confirmantes que le acompanian son: Cixila, Dulcidio de Zamora, Rosendo de Mondoñedo y Oveco de León.

53 Edit. en J. DEL ÁLAMo, Colección diplomática de San Salvador de Oña (822-1284). Madrid, CSIC, 1950, tomo I, doc. 3, p. 6. En este caso aparece como único obispo confirmante.

54 Al menos, el 9 de febrero de 937 se documenta la existencia de un Julianus Hispalensis Episcopus, en E. Flórez, ob. cit, tomo XVI, p. 437.

55 En dicho lugar y año, el 31 de agosto, se cita a un obispo Julián que posiblemente sea el mismo obispo palentino. Tal cita se halla en un diploma del rey Ramiro II en el que confirma diversas donaciones al monasterio de San Julián de Samos, edit. en J. RoDrigueZ, Ramiro II, rey de León. Madrid, CSIC, 1972, doc. 3, p. 601 .

56 Ya que Gonzalo Martínez Díez ve muy posible que el Julianus episcopus testis citado el 29 de abril de 950 en un diploma de Cardefia, que documenta una donación en las proximidades de Burgos, sea el mismo que el obispo de Palencia. El diploma se halla editado en L. SERRANo, Becerro Gótico de Cardeha. Valladolid, 1910 , pp. 362-3.

Actas del I Congreso de Historia de la Iglesia y el Mundo Hispánico Hispania \$acra, 52 (2000) 
También se conoce por fuentes musulmanas su posible intervención como testigo en el tratado de paz suscrito en el verano de 941 entre Ramiro II y el califa Abderrahman III ${ }^{57}$.

Los sucesores de este obispo palentino de nombre Julián, si los hubo, no han aflorado en la documentación contemporánea.

Esta primera restauración de la sede palentina en la persona del obispo Julián que parece estrechamente ligada a la creación del condado de Monzón y de su primer conde, Asur Fernández, resultó, pues, un tanto efimera y de corta duración; sólo tuvo una existencia de veinte afíos, de 931 a 950 como máximo, y a su frente únicamente habria figurado un único prelado, don Julián. Por lo que no es de extranar que este primer intento de restauración haya pasado un tanto desapercibido y que incluso algunos estudiosos de la historia eclesiástica de Palencia hayan negado la existencia de este primer intento fallido y la del propio obispo Julián, como Fernández del Pulgar ${ }^{58}$.

En la segunda mitad del siglo $X$ ya no existe, pues, ninguna referencia documental a otro obispo de Palencia. En cambio, contemporáneo al anterior intento aparece documentada una supuesta diócesis de Bamba, directamente relacionada con la persona de otro obispo, de nombre FRUNIMIO.

La primera vez que este prelado se manifiesta en la documentación bajo la denominación de episcopus bambensi sedis, es el 20 de febrero de 938, suscribiendo la donación de una serie de propiedades hecha por el rey Alfonso IV en favor de los monasterios de Santa Eugenia de Calaberas y de Sahagún ${ }^{59}$. Ese mismo año, 938, el 16 de julio está fechada la suscripción del códice canónico de San Juan de la Peña, hoy perdido, expresando que había sido escrito en el monasterio de «Ubambe» por el diácono Nuño, bajo el gobierno del obispo Frunimio $^{60}$. Diez años después, exactamente el 25 de mayo de 948 , vuelve a

${ }^{57}$ Entre los testigos de dicho acuerdo de paz aparece «el obispo Juliány, del que no especifica la sede que regía. Vid. IBN HAYYAN, de Córdoba, Crónica del califa Abdarrahman III an-Nasir entre los años 912 y 942 (al-Muqtabis V). Traduc. de $\mathrm{M}^{2}$. Jesús Viguera y Federico Corriente. Zaragoza, Anúbar Ediciones, 1981, p. 351 .

${ }^{58}$ P. FeRnANDEZ DEL PUlgar, ob. cit., libro I, pp. 678 y ss.

59 Publ. por J. M. MANGUEZ FERNÁNDEZ, ob. cit., doc. 70, para quien «existen pruebas inequívocas de falsificación integral del documentom. Algunos autores, como Escalona y Vignall, consideran que la discordancia existente entre la fecha que posee la carta y el rey reinante se debe a que el escriba le aftadió equivocadanente una "X", por lo que considetan que el afto correcto sería el de 928, en pleno reinado de Alfonso IV (925-93I).

60 "Conpletusque in monasterio Ubambe a Nunno diacono licet indigno sub regimine Frunimii episcopi», en M. GÓMEZ MORENo, Iglesias mozárabes. Arte espah⿱ö de los siglos $L X Y X$. Madrid, Centro de Estudios Históricos, 1919, p. 195. Afnos más tarde, este diácono Nuño aparece confirmando varios documentos de los reyes Ramiro II (945) y Ordofo III (951), como abad del monasterio de Santa María de Bamba, en J. M. MingueZ FERNÁNDEZ, ob. cit, docs. 97, 98, 99 y 132.

Actas del I Congreso de Historia de la Iglesia y el Mundo Hispánico Hispania Sacra, 52 (2000) 
confirmar, bajo el título de Dei gratia episcopus Bambensae sedis, otra donación, en este caso de la iglesia de San Juan Bautista y Santa Colomba, realizada por el obispo Vimara a su primo hermano Alfonso ${ }^{61}$.

Harto dificil resulta aclarar el curriculum vitae de este Frunimio, obispo de Bamba, entre otras cosas, porque en el mismo tiempo coinciden aparentemente, al menos, tres obispos de idéntico nombre: Frunimius episcopus legionensis, Frunimius episcopus Secoviensis sedis y, el que nos ocupa, Frunimius episcopus bambensi sedis ${ }^{62}$. Gómez Moreno cree, siguiendo a Risco ${ }^{63}$, que este último Frunimio «debe ser aquel obispo de León, bien conocido, que duró allí hasta enero de 928, cuando hizo testamento en favor de su Catedral, donándola fincas y objetos, y que luego vivió retirado, hasta 953 , a lo menos) ${ }^{64}$; únicamente difiere de la tesis de Risco en el lugar de su retiro, pues, mientras para éste fue San Andrés de Perameno por la intervención que tuvo a favor de sus ermitafios en 944, Gómez Moreno piensa que los datos en favor del retiro en Santa María de Bamba son más concluyentes, siendo posible que, incluso, hubiera sido este mismo obispo el fundador del monasterio siguiendo el ejemplo de su predecesor, el obispo Cixila, que se retiró al monasterio de San Cosme de Abellar por él fundado.

Palomeque Torres participa plenamente de la tesis de Risco al perfilar la historia de este personaje en la sede de León, que, después de haber padecido destierro por mandato del rey Fruela II, renunció al obispado para retirarse al monasterio de los ermitaños de Perameno, donde profesó la vida monástica ${ }^{65}$, si bien cae en contradicción al tratar como dos personas distintas, al obispo de León y al de Bamba, en una ocasión $n^{66} e$ identificarlos en otra ${ }^{67}$. Posibilidad ésta última de la que se muestra más partidario Justiniano Rodríguez cuando equipara al Frunimio, obispo de Bamba, con el Frunimio, obispo cesante en la prelacía legionense por la venalidad del rey Fruela, aun cuando no se le oculta, de otra parte, «la posibilidad de que este Frunimius episcopus bambensis sea distinto del obispo de León y haya más bien de identificarse con el Frunimio obispo de Segovia) ${ }^{68}$.

\footnotetext{
6l J. RoDkiguez, ob. cit., doc. 64.

62 Incluso, también aparece documentado por esta misma época y territorio un abad de idéntico nombre. Vid. J. M. MANGUEZ FERNANDEZ, ob. cit., doc. 28.

${ }^{63}$ M. Risco, España Sagrada. Madrid 1784, tomo XXXIV, pp. 222-36.

${ }^{64}$ M. GÓMEZ MORENo, ob. cit., pp. 195-96.

65 Vid. A. Palomeque Torres, Episcopologio de las sedes del reino de León. León, Centro de Estudios e Investigación «San Isidoro», 1966, pp. 69-85.

${ }^{66}$ Ibidem, p. 73.

${ }^{67}$ Ibidem, p. 82.

68 J, RODRIGUEZ, ob. cit., p. 399-400 y not. 22.
} 
Efectivamente, como bien apunta Reglero de la Fuente ${ }^{69}$, parece más problemática la identificación de Frunimio, obispo de Bamba, con su homónimo leonés que con su también homónimo segoviano, si es que hay que identificarlo con alguno de los dos y cada uno de ellos no constituían personas distintas. Contra la primera opción, es decir la identificación del Frunimio, obispo de León, con el Frunimio, obispo de Bamba, juega la coincidencia del obispo leonés y de otro obispo, de nombre Frunimio, del que no se expresa sede alguna ${ }^{70}$, como confirmantes de dos documentos fechados el 26 de junio de 917 y el 12 de enero de 928 , respectivamente ${ }^{71}$, y, sobre todo, la también coincidencia del Frunimio, obispo leonés, con el Frunimio, obispo de Segovia, como confirmantes en el acta fundacional del monasterio de San Cosme y San Damián de «Abeliar» por el obispo Cixila el 5 de noviembre de $927^{72}$. Mientras que la segunda opción, la identificación del Frunimio de Bamba con el de Segovia, no plantea ningún obstáculo aparente y resulta un claro precedente del caso de identificación entre el obispo de Simancas y el de Segovia, sucedido décadas después.

$\mathrm{El}$ intento más consistente $\mathrm{y}$, a la postre más peligroso para los intereses de los obispados vecinos de Astorga y León, de implantar una sede episcopal en tierras palentinas fue el que tuvo lugar en la estratégica plaza fuerte de Simancas y en la persona del obispo LLDEREDo.

Aunque es difícil precisar los orígenes, ciertamente confusos, y las razones de la erección de este obispado, su existencia ya había sido puesta de manifiesto en el siglo XVIII por Flórez ${ }^{73}$ y Risco ${ }^{74}$ a partir de la publicación de dos diplomas diferentes y procedentes de los archivos de las catedrales de Astorga y León, respectivamente, que tratan sobre la supresión de dicha sede por Ramiro III el año 974. Si bien, fue Sánchez-Albornoz quien en 1925 puso las bases sobre el origen y vicisitudes de este obispado, al demostrar la falsedad de los

69 C. M. REglero de LA FUENTE, Espacio y poder en la Castilla medieval. Los Momtes Torozos (siglos $X$-XIV). Valladolid, Diputación Provincial, 1994, p. 314.

${ }^{70}$ Por lo que existe una gran probabilidad de que fuera el regente de la sede episcopal de Bamba o de Segovia, si es que eran distintos.

${ }^{71}$ Publicados ambos en G. DEL Ser QUJJano, ob. cit., docs. 10 y 12 y en E. SÁEz, ob. cit., docs. 43 y 76. Se trata de dos donaciones de diversos bienes realizadas por el obispo leonés, Frumimio, en favor de la iglesia de Leon.

72 E. SÁEZ, ob. cit., doc. 75.

${ }^{73}$ E. FLórez, ob. cit, tomo XVI, pp. 123, 160 y 443. Para este autor, el fundador del obispado de Simancas habría sido Ordoño I, hijo de Ramiro I.

${ }^{74}$ M. Rusco, ob. cil., tomo XXXIV, pp. 245, 283-87 y 466-69. Risco atribuia la creación de este obispado al capricho del rey Alfonso IV, quien no dudo en segregar temerariamente para ello una parte del territorio correspondiente al de Leon y erigir una silla episcopal en esta villa, a la que el rey mencionado tenía singular afición. Fechaba esta acción el afio 927.

Actas del I Congreso de Historia de la Iglesia y el Mundo Hispánico

Hispania Sacra, 52 (2000) 
dos diplomas anteriores y aportar un tercero, también procedente del archivo de la catedral de Astorga $^{75}$, que a pesar de las dudas suscitadas en algunos historiadores ${ }^{76}$ sobre su autenticidad y originalidad, hoy se tiene por verídico ${ }^{77}$.

Sánchez-Albornoz liga el origen de este obispado a la victoria de Simancas en 939 y a las posteriores conquistas y repoblaciones realizadas por castellanos y leoneses al sur del Duero (Sepúlveda, Ledesma, Salamanca, Alba, etc.). Los amplios territorios situados a orillas de este río, alejados de las sedes episcopales de Astorga, León y Oviedo, y sus moradores necesitaban un pastor y para dárselo, el rey Ordoño III, sustrayendo de las diócesis de Astorga y León algunos territorios, decretó la creación de un obispado con sede en la plaza fuerte de Simancas, repoblada por Alfonso III a fines del siglo IX, lo dotó copiosamente y colocó a su frente al obispo Ilderedo ${ }^{78}$. Estos hechos pudieron ocurrir el año 953, el mismo en que el creador de este obispado, Ordoño III, realizó una dona-

75 Reimp. en C. SÁNCHEZ-ALBORNOZ, ob. cit., pp. 381-404.

${ }^{76}$ Como A. QunTtana Prieto, El obispado de Astorga en los siglos LX y X. Astorga 1968, pp. 1314. Este autor explicita como falsos cinco documentos, «que giran unánimente alrededor de pretendidas devoluciones de territorios a los obispos de León y de Astorga, apoyándose en la supresión de un supuesto obispado inexistente", agregando sobre el cuarto, el que nos ocupa, «creo que se trata de una falsificación más. Solamente el contenido, calcado en el documento primero, lo hace bastante sospechoso. Con esto por delante, he examinado detenidamente el pergamino, que aún se custodia en el archivo catedralicio de Astorga, $y$ he de confesar que no resiste un serio estudio paleográfico, que le dedicaré en la primera oportunidad que se me presente, y que ahora no intento por no estimarlo conducente ni necesarion.

También D. Mansilla Reoyo, $a b$. cit, tomo II, pp. 41-45 considera falso el documento en cuestión, lo que le conduce a «optar por un veredicto negativo sobre la supuesta diócesis de Simancas... Las falsificaciones de los documentos son, sin duda, el más fuerte argumento en contra de la "supuesta diócesis de Simancas". No hubo tal obispado, lo que hubo fue una manipulación de documentos forjados en los talleres de las curias djocesanas de León y Astorga principalmente, con motivo de las disputas surgidas sobre límites o creación de nuevas diócesis en los siglos XI-XII".

77 «Por mi parte he examinado también muy detenidamente la transcripción del điploma que incluye Sánchez-Albornoz en su trabajo llegando a la conclusión de que se trata de un documento auténtico, sin ningún viso de falsedad, con un vocabulario, unas instituciones, unos personajes y una estructura documental que responde en todo a los diplomas reales leoneses del siglo X's. Así se expresa J. M. Rulz AsENCIO, «La provincia de Valladolid en la Alta Edad Media (siglos VII-XI)", Historia de Valladolid. II Vallodolid Medieval. Valladolid, Ateneo, 1980, p. 34. También se decantan por la autenticidad de este documento y la falsedad de los anteriores G. DEL SER QUUJANO, ob. cit., doc. 34 y pp. 28 y ss. y E. SÁEZ y C. SAEZ, ob. cit., doc. 436.

78 J. RoprfauEz, ob. cit., pp. 394-401 opina que el origen del obispado de Simancas fue notoriamente irregular; y que esta situación pudo remontarse al obispo de Bamba. Frunimio, que se constituiría, así, en el precedente de Ilderedo, obispo de Simancas, cuya consagración real en el 953 habría significado el fin de dicha irregularidad canónica. Por lo que la «decisión de Ordofio III no consistió en la creación ex novo de una diócesis sin precedentes, sino la legitimación y consagración normal de una situación o hecho social y religioso más o menos arraigado y definido en una organización administrativa eclesiástica que acaso databa de varios afios antesn.

Actas del I Congreso de Historia de la Iglesia y el Mundo Hispánico Hispania Sacra, 52 (2000) 
ción al obispo de León, Gonzalo, de todas las iglesias que construyeron en el alfoz de Salamanca los pobladores leoneses en tiempos de su padre, Ramiro II, posiblemente como compensación de la pérdida de una porción de su obispado sufrida al erigirse el de Simancas ${ }^{79}$.

Ilderedo, quien, en ocasiones, también aparece bajo la titulación de obispo de Segovia ${ }^{80}$, acaso en atención a la jurisdicción que tal vez ejercía sobre tierras pertenecientes a esta diócesis o en un intento de legitimación al enlazar con la tradición goda, gobernó el obispado de Simancas hasta al menos finales de 963 en que se halla documentado por última vez; se trata de su confirmación, como episcopus de Septemancas, de una donación realizada al monasterio de Sahagún por los hermanos Ansur y María ${ }^{81}$.

A Ilderedo le sucedió en dicha sede el obispo TEODiscLo, quien ya la regía el año 967, primer documento conocido en que se constata su existencia como obispo simanquino; en esta ocasión también se trata de su confirmación de una venta realizada por los diáconos Álvaro y Abraham al obispo leonés Velasco el 14 de julio de $967^{82}$.

Teodisclo fue el último obispo en regir la diócesis de Simancas, ya que a su muerte, acaecida en 974, los obispos de Astorga y León, que se sentian perjudicados con la erección de este obispado, presionaron a la regente Elvira, tía y tutora del rey niño Ramiro III, para su supresión y la consiguiente recuperación de los territorios perdidos. Con su petición lograron la convocatoria de una asamblea extraordinaria de Palacio y, en su reunión que tuvo lugar a fines de julio de 974 , todos los prelados y magnates del reino abogaron por la supresión de la diócesis de Simancas, por la devolución a León de la ciudad de Simancas y a Astorga de las decanías de Toro y por la no elección ni consagración de

${ }^{79}$ C. SÁNCHEZ-AlbORNOZ, ob. cit., p. 386. Dicha donación se halla publicada en G. DEL SER QUIJANo, ob. cit., doc. 26 y E. SÁEZ y C. SAEZ, ob. cit., doc. 260. Por su parte, A. Palomeque TorRes, ob. cit., p. 246, apunta que el obispo Ilderedo habia sido consagrado un año antes, ya que el primer testimonio existente de un obispo de idéntico nombre se halla en una escritura otorgada por Ordofo III el 11 de noviembre de 952 a favor de la iglesia de Santiago y de su obispo Sisnando II. Por otra parte, J. M. RUZZ AsENCto, ob. cit., p. 34, seffala el 952, como el año en que pudo erigirse dicho obispado, al estar documentada la presencia de Ordoño III en Simancas el 1 de agosto de 952.

Bo «llderedus, Dei gratia aepiscopus, Segouiense aepiscopus»; así se titula el 6 de diciembre de 960 en un diploma en que concede a la iglesia de León y a su obispo Gonzalo la villa de San Claudio, en la ribera del Valderaduey, y una serna junto a dicha villa. Publ. en G. DEL SER QUUJANO, ob. cit., doc. 30 y E. SAEZ Y C. SAEZ, ob, cit., doc. 333.

BI Publ. por J. M. Minguez FernANDEZ, ob. cit, doc. 215. En esta misma colección documental se constata la presencia de este obispo confirmando los siguientes documentos: 165, 167, 168, 171 y 183.

82 Publ. en G. DEL SER QuJjaNo, ob. cit., doc. 32 y en E. SÁEZ y C. SAEz, ob. cit., doc. 403 . Dos años después, se vuelve a documentar su presencia en esta ocasión, en una donación que él mismo realiza en favor del monasterio de Sahagún, vid. J. M. MingueZ FerNÁNDEZ, ob. cit., doc. 253.

Actas del I Congreso de Historia de la Iglesia y el Mundo Hispánico Hispania Sacra, 52 (2000) 
sucesor de Teodisclo. A todo ello accedieron los monarcas leoneses, ratificando dicho acuerdo el 29 de julio de 974, al ordenar torn[are ipsam ciui]tatem cum suis adiacentiis post partem sedis legionensem et ad pontificem domnum Sisinandum, et omnes alias decanias uel cunctis adiuntionibus tornare in propriis sedibus antiquis unde aliquid abstulerunt. Idicirco nunc et deinceps tornamus etiam post partem sedis asturicensem et uobis ant [istitem nostrum] domnum Gundisaluum aepiscopum, uel ad eos qui post ubidem obtinuerint ordo, medietatem de ipsas decaneas de Tauro ab omni integritate; secundum a prioribus de idem sedis fuit prius possessas ${ }^{83}$.

Tal fue la historia del fugaz obispado de Simancas, cuya vida, al igual que los anteriores intentos fallidos de Palencia y Bamba, apenas si sobrepasó los veinte años, de 952 a 974 como máximo.

El mismo ańo de la supresión del obispado de Simancas parece existir un cuarto y ultimo intento de crear un nuevo obispado en los antiguos territorios palentinos, en esta ocasión su sede se sitúa en el lugar, asimismo estratégico, de Duefias y en la persona del obispo SINDONIO, del que se carece de cualquier otra información, salvo la extraída por el profesor Julio González del Índice del monasterio de San Isidro de Dueñas ${ }^{84}$.

Estos son los intentos hasta ahora documentados de restaurar o crear nuevos obispados en los territorios pertenecientes a la extinta diócesis palentina, antes de su definitiva restauración en la primera mitad del siglo XI. Se trata, ciertamente, de múltiples intentos, en ocasiones simultáneos, centrados en distintos lugares (Castro Vivester, Palencia, Bamba, Segovia, Simancas y Dueñas), lo que parece evidenciar la indudable necesidad sentida de implantar una administración eclesiástica propia en el amplio territorio que se extiende entre la cordillera Cantábrica y el sur del río Duero y entre el Cea y el Pisuerga. Sin embargo, la duración de cada uno de estos tanteos fue muy efímera. Sus vidas se limitaron a la existencia del prelado fundador; con su muerte también desaparecía la silla episcopal. La única excepción la constituyó el obispado de Simancas, cuya cátedra estuvo regida por dos obispos de forma consecutiva. Por otra parte, mientras los intentos de restaurar las antiguas sedes episcopales de Palencia y Segovia y de crear las nuevas de Bamba y Dueffas no contaron con la oposición, al menos explícita, de los obispos de las diócesis limítrofes, como Oviedo, Astorga y León, que desde muy pronto habían proyectado sus apetencias expansionistas sobre este territorio, sin reparar en falsificar documentos con tal fin, como, por ejemplo, los atribuidos a Alfonso III y Ordofio II, en los que se seña-

83 C. SÁNCHEZ-ALBORNOZ, ob. cit., pp. 393-94.

4. J. GonzAl.ez, "V Siglos de Reconquista", Historia de Palencia. Volumen I: Edades Antigua y Media. Palencia, Excma. Diputación Provincial, 1984, p. 182. 
lan los límites de las diócesis de Oviedo y León, el intento de constituir una circunscripción eclesiástica, centrada en la plaza fortificada de Simancas, contó con una férrea y, a la postre, eficaz oposición de los obispos de León y Astorga.

Estos elementos diferenciales, además de la solemnidad del foro en que se pidió su supresión, parecen apuntar a que el único intento serio por erigir un nuevo obispado, una administración eclesiástica regional diferenciada al sur de los montes cántabros y entre los ríos Cea, Pisuerga y Duero, fue el iniciado por Ilderedo y continuado por Teodisclo en la ciudad de Simancas. En los otros casos los intentos parecen más aparentes que reales, porque, sin duda, se trataba de lugares que recibían el título de sedes episcopales no por constituir el centro administrativo de una circunscripción territorial eclesiástica, sino por el simple hecho de residir en ellos obispos dimisionarios y sin jurisdicción pastoral, obispos que con anterioridad habían perdido, no importa la forma, su verdadera sede episcopal ${ }^{85}$.

Alegar la pérdida de autonomía del condado de Monzón y su integración, como uno más de los otros (Álava, Castilla y Asturias de Santillana) que gobernaba el conde castellano Sancho Garcés, en la práctica independiente de León, como explicación al fracaso de restauración de la sede palentina en el siglo X, parece no responder a la realidad. En este caso, como en los de Bamba y Dueñas, no hubo fracaso alguno; en ningún momento se pretendió la continuidad de sus sedes episcopales; desaparecido el obispo residente, desaparecía el título asignado al lugar de residencia. Para el caso de Simancas, curya erección carecía de tradición, es indudable que la presión ejercida por los obispos de Astorga y León sobre el rey niño y su tía la regente para su supresión y la devolución de lo que antes les pertenecía, así como el escaso desarrollo del proceso repoblador en el centro de la Extremadura, al sur de Simancas, en el 950, jugaron en su contra. Pero, sin duda, el hecho de que el obispado de Simancas no cristalizara y del retraso de la definitiva restauración de la diócesis palentina hasta bien avanzado el siglo XI no es otra que la profunda crisis interna que entonces atra-

${ }^{85}$ A no ser que se estuviera produciendo una situación ya apuntada por M. C. DíAZ Y DíaZ, «Origenes cristianos en Lugow, Actas del Coloquio Internacional sobre el Bimilenario de Lugo. Lugo 1977, p. 245 y por M. I. LóRING GARCí, ob. cit., pp. 200-01 para una época anterior: la coexistencia de varios obispos en el mismo territorio obedecía a que esta primitiva organización eclesística palentina no se ajustaba al sistema tradicional, conforme al cual sólo las comunidades mayores, las urbanas, situadas en cabeza de distrito eran dirigidas por un obispo, sino que se significaba «por contar con una organización especifica caracterizada por la abundancia de episcopados, fenómeno resultante de la erección de éstos tanto en las civitates normales, como en los castella, en los loca de los dominios imperiales (fundi) o de los privados (villae), e incluso en asentamientos indígenas», y que corre paralelo a la cristianización del campo, aunque las autoridades eclesiásticas desde muy pronto procuraron eliminarlo. 
vesó el reino leonés, agravada por la inmediata aparición en la escena política y militar del hayib amirí Almanzor, con las consiguientes secuelas destructivas ocasionadas por las sucesivas campañas que las tropas musulmanas realizaron contra los reinos hispanocristianos.

Las razias de Almanzor se inician en el $977^{86}$; de ellas la que tuvo consecuencias más negativas para las tierras palentinas al norte del río Duero fue la dirigida contra Simancas. El ataque contra esta plaza fuerte, que dominaba estratégicamente el paso de los ríos Duero y Pisuerga, se produjo en el verano de 983, en los últimos días del mes de junio o primeros de julio, ya que partió de Córdoba el 16 de junio y regresó el 17 de julio, después de 32 días de campaña ${ }^{87}$. El rey leonés, Ramiro III, contando con el apoyo del conde castellano, García Fernández, y del rey navarro, Sancho Abarca, salió a su encuentro, pero fueron derrotados por el caudillo amirí que de esta forma vengó la afrenta que cuarenta y cuatro años antes Ramiro II había inflijido a Abd al-Rahman III en ese mismo escenario. Un documento del archivo de la catedral de Santiago relativo a la donación del rey Bermudo II a la iglesia de Santiago de varios bienes en Zamora, que habían pertenecido a Domingo Sarracino, muerto en Córdoba ${ }^{88}$, narra la toma de Simancas por Almanzor, así como las calamidades padecidas por los prisioneros capturados. Llegado el ejército musulmán a Simancas, la sitiaron hasta que, derruidos sus muros y quebrada su puerta, pudieron penetrar al interior, matando con la espada a la mayor parte de los moradores y conduciendo en cautividad a Córdoba a los pocos que se salvaron de la matanza, entre los que se encontraba el citado Domingo Sarracino. Allí, después de permanecer encarcelados más de dos años, fueron decapitados (gladio interfectos).

Que la caída de Simancas supuso una sensible pérdida para el reino leonés queda perfectamente patente al comprobar que el suceso fue recogido en distintas fuentes documentales, como diversos diplomas, Anales y Cronicones, un tipo de fuentes narrativas, estas últimas, que, como bien indica el profesor Ruiz

${ }^{86}$ La primera aceifa de Almanzor contra territorios cristianos tuvo lugar del 24 de febrero al 17 de abril de 977 y se dirigió contra Los Bafios de Ledesma, en la parte occidental de Salamanca. Vid. J. M. RuZz AsENCIO, "Campañas de Almanzor contra el teino de León (981-986)», AEM, 5 (1968), pp. 56-57.

${ }^{87}$ Con estas escuetas palabras narra el geógrafo almeriense Ahmad ibn Umar ibn Anas al-Udri (1003-1085) dicha expedicion: «Hizo Muhammad ibn abi Amir la campaña de Simancas. Fue la que hizo perecer al tirano. Fue una aceifa de una penetración. [Partió] el sábado 2 de muharram del afio 373 (-16 junio 983), que correspondió al 14 por andar del mes de junio. Volvió el martes, 4 de safar $(=17$ julio 983), al cabo de 32 diass, en lbidem, p. 62.

${ }_{88}$ Aunque este documento, en la forma que hoy se conoce, fue rehecho en el siglo XII y, por consiguiente, diplomáticamente es falso, sin embargo desde el punto de vista del contenido histórico se le considera verídico. Su datación, aunque plantea algunos problemas, es el 7 de febrero de 986 . Publ. en M. LuCAs Álvarez, Documentación del tumbo de la catedral de Santiago de Compostela. Estudio y edición. León, Centro de Estudios e Investigación «San Isidoro», 1997, doc. 52. 
Asencio, «sólo registran los hechos muy grandiosos, y es notoria su particular proclividad hacia las grandes tragedias colectivas» ${ }^{89}$. Pero esta acción bélica de Almanzor no sólo supuso la destrucción de la estratégica ciudad de Simancas, sino que, además, es lógico pensar que todo el poblamiento rural del territorio circundante tuvo que verse afectado negativamente; la mayoría de sus habitantes huirían a zonas septentrionales, buscando salvarse de unas acciones musulmanas que, al contrario que la invasión del siglo VIII en su mayor parte pacífica, consistian en sistemáticas y hostiles expediciones de saqueo y destrucción de bienes y personas. Además, cabe pensar, y más si se tiene en cuenta que esta situación se va a repetir hasta principios del siglo XI, que otros centros y territorios palentinos más al Norte, como Dueñas y en especial la propia ciudad de Palencia, carente de buenas condiciones naturales para la defensa, pudieron sufrir consecuencias similares a las padecidas por el territorio de Simancas: una merma total o parcial, pero en todo caso considerable, de su población, lo que puede explicar el panorama de desolación y abandono que de aquel centro traslucen las fuentes narrativas y los diplomas reales relacionados con la posterior restauración de su diócesis, uno de los cuales presenta a Palencia como una pequefía villa que, despojada de su anterior carácter de centro administrativo de un territorio, ha entrado a formar parte de otro territorio y a depender, por tanto, de otro centro administrativo más importante, la villa de Monzón ${ }^{90}$.

\section{LA DEFINITIVA RESTAURACIÓN DE LA DIÓCESIS PALENTINA: UN PUNTO DE PARTIDA LEGENDARIO Y CONFUSO}

Así pues, al finalizar el primer milenio ninguna circunscripción administrativa eclesiástica diferenciada regía el antiguo territorio diocesano palentino; éste en su mayor parte permanecía bajo los dominios de los obispos convecinos, formando parte de tales diócesis ${ }^{91}$ a pesar de que a lo largo del siglo X se había sentido la necesidad e, incluso, vanamente se había intentado crear en

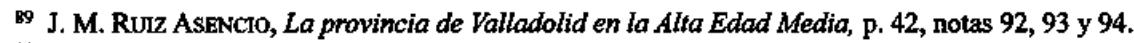

90 «uilla uocitata Palencia, in territorio Monteson, prope alueo Karrion», asi se la ubica en el diploma de Bermudo III; mientras que la crónica-relato de la restauración de la sede episcopal palentina, expresa que la ciudad «iacebat sentuosa et inculta et a fundamento destructa, que ante fuerat subarrata multis uiris», publ. en T. ABajo MaRTfN, ob. cit., docs. 1 y 4.

${ }^{91}$ El privilegio del rey Fernando I de 29 de diciembre de 1059 expresa lo siguiente: «Post multum, uero, temporis, regnante piisimo Aldefonso rege, tio et socero meo, Deo restaurante Christianitatem et destruente ismaelitanum gente, uicini episcopi diuisserunt sibi palentinum episcopium per sortems, $I b i$ dem, doc. 9. 
varias ocasiones una específica que englobara las tierras del Carrión y del Pisuerga, a modo de cuña entre los obispados de Oviedo al Norte, León y Astorga al Oeste, y Burgos al Este, en un espacio objeto de frecuentes disputas por las dos potencias políticas de León y Castilla. Sólo la quiebra del estado califal cordobés y el surgimiento de los reinos taifas a principios del siglo XI y, con ellos, su debilitamiento político y militar, posibilitó la realización de esa necesidad restauradora largamente sentida y centrada en la ciudad de Palencia, al contar ésta con la base jurídica y consuetudinaria más sólida y estar respaldada por la ideología neogótica dominante en la monarquía asturleonesa. Era directamente el rey quien decidía la erección de nuevos obispados o la restauración de los extintos en los territorios reconquistados, como un aspecto más de su política interna de la organización administrativa del reino. Y la fuerza de la tradición, como bien refiere Mansilla Reoyo, «era tan grande y las antiguas listas de sedes y provincias eclesiásticas seguían ejerciendo una influencia tan grande a través de la reconquista que no era fácil introducir en ellas un cambion ${ }^{22}$.

Las informaciones sobre la definitiva restauración de la sede episcopal palentina provienen de dos tipos de fuentes de características distintas. Pero ambas por motivos también distintos dificultan el exacto conocimiento del hecho.

\subsection{La restauración legendaria}

La restauración de la sede episcopal palentina se halla envuelta en una leyenda prodigiosa que habría circulado oralmente a fines del siglo XI y principios del XII ${ }^{93}$, siendo recogida y fijada por escrito, sin el más mínimo atisbo de duda, dos siglos después del supuesto acontecimiento por dos principales crónicas espaniolas del siglo XIII.

La primera, en orden cronológico de redacción, es la Historia de rebus Hispanie, también conocida como Historia Gothica, sin duda la obra cumbre de la cronística hispanolatina de época medieval; se debe al arzobispo de Toledo, don Rodrigo Jiménez de Rada (1170-1247), quien la terminó hacia el año 1243. Y en ella se recoge por primera vez, dándole crédito ${ }^{94}$, el siguiente relato de la historia del rey Sancho III de Navarra:

92 D. MANSHLA ReOYo, ob. cil., tomo II, p. 27.

93 J. GonzÁlez, Siglos de Reconquista, p. 182.

94 Rodrigo Jiménez de Rada fue propenso a dar crédito a esta leyenda «por tratarse de una iglesia sufragánea de la toledana y por ser navarro el reym, en $\mathrm{lbidem}$, p. 182. 
"Hic Sancius, dum quadam die se in uenationis studio recrearet, aprum secutus contigit in ciuitate olim nobili, tunc deserta, que Palencia dicebatur, criptam in forma ecclesie inuenire et altare in honore sancti Antonini martiris adhuc extans; ad quam cum aper fugiens aduenisset et rex uibrato uenabulo feram in cripta occidere uoluisset, diuino percussus miraculo, quod proposuit non potuit adimplere; obriguit enim brachium eius dextrum et sic aper illesus euasit. Rex autem conuersus ad preces beati martiris Antonini suffragium implorauit, et ilico restitutus iussit ciuitatem dirutam reparari et super criptam ecclesiam hedificari, et procurauit ibidem episcopum consecrari et totam ciuitatem cum omnibus terminis et pleno dominio episcopo et ecclesie donatione optulit liberali, uillas et possessiones alias superaddens, quibus adhuc hodie gaudet ecclesia Palentinan ${ }^{95}$.

La segunda crónica del siglo XIII en narrar y difundir el hecho milagroso de la restauración de la sede episcopal palentina es la Primera Crónica General. Aunque mandada componer por el rey Alfonso X, su redacción no llegó a iniciarse hasta el affo 1270; su primera parte se terminó hacia 1280 y la segunda se continuaba bajo el reinado de Sancho IV, en 1289. Su versión algo más detallada del suceso narrado es como sigue:

«Este rey don Sancho seyendo en Castiella, corrie un dia mont, et acaescio que fallo un dia un puerco montes; et yendo empos el, metiosele en una çibdad que estaua estonces yerma -et es aquella a que agora dizen Palencia- et entro en una cueua que auie y fecha en guisa de eglesia, et en ella un altar fecho a onrra de sant Antolin martir -et ell altar es aquel que oy en dia esta y aun muy onrrado et de grandes uertudes- et el rey quel quisiera matar dentro en aquel santo logar, feu ferido del Nuestro Sennor dios por un miraglo quel contescio y: que assi como le el quisiera ferir con el uenablo, que se le torcio el braço diestro de guisa quel non pudo tanner. Et por este auenimiento finco el puerco quel non mato. Et el rey quando aquello uio, echosse luego a priezes en oracion, et rogo a la piedad de sant Antolin martir de todo coraçon quel ouiesse mercet et quel tolliesse aquell mal. Et el rey fue luego sano de su braço. Empos esto finco alli el rey don Sancho algunos dias, et poblo aquella çibdad muy bien, que estaua antes yerma; et fizo y una grand eglesia sobre la cueua, et establecio y obispo, et fizo la çibdad obispado, et dio all obispo et a la eglesia

${ }^{55}$ R. JIMÉnEZ DE RADA, Historia de rebus Hispanie sive Historia Gothica, Tvrnholt, Brepols, 1987, lib. VI, cap. VI, p. 184. «Este Sancho, un dia en que se entretenía con su afición a la caza, persiguiendo a un jabalí encontró por casualidad, en una ciudad antafio noble y que entonces estaba abandonada, llamada Pajencia, una cripta en forma de iglesia y un altar, que aún se mantenía en pie, en bonor del mártir San Antonino. Y como el jabali llegase a aquélla en su huida y el rey se dispusiera a matarlo en la cripta blandiendo su lanza, tocado por un milagro del cielo no pudo llevar a cabo lo que se proponía; pues se le inmovilizó su brazo derecho y de esta forma el jabalí escapó indemne. Entonces el rey, postrado en oración, suplicó la ayuda del santo mártir Antonino y, restablecido al instante, ordenó reconstruir la ciudad derruida y levantar una iglesia sobre la cripta, y se encargó de que alli mismo fuera consagrado un obispo, e hizo, a éste y a la iglesia, generosa donación de toda la ciudad con todas sus tierras en pleno dominio, añadiéndole otras villas y posesiones de las que aún hoy disfruta la iglesia palentina», traduc. de Juan Fernández Valverde en R. JIMÉNEZ DE RADA, Historia de los hechos de España. Madrid, Alianza Editorial, 1989, pp. 227-228.

Actas del I Congreso de Historia de la Iglesia y el Mundo Hispánico

Hispania Sacra, $52(2000)$ 
en donadio tod aquella noble çibdat et con todos sus terminos et con todo su sennorio, et que siempre fuesse libre de todo sennorio et de toda premia; et aun sobresto acresciol otras uillas et heredades muchas, porque es oy en dia muy rica et muy abondada aquella eglesia de Palencian" ${ }^{96}$.

Independientemente de las ligerísimas variantes de estas dos versiones cronísticas, esta fantasmagórica leyenda que pretende otorgar un carácter sobrenatural a la restauración episcopal de Palencia carece de originalidad, ya que el hallazgo de un lugar sagrado de forma ocasional, cazando un jabalí, un ciervo o una perdiz, también aparece en las narraciones fundacionales de otras muchas instituciones eclesiásticas, como, por ejemplo, de los monasterios castellanos Santa María de Aguilar de Campóo erigido hacia el año 950 por el conde Osorio Armíldez con la ayuda del abad Opila ${ }^{97}$, y San Pedro de Arlanza restaurado por el conde Fernán González ${ }^{98}$; del asturiano San Antolín de Bedón fundado por el conde Muńazán ${ }^{99}$; del navarro Santa María la Real de Nájera edificado en

${ }^{96}$ Primera Crónica General. Estoria de Espania que mandó componer Alfonso el Sabio y se contimuaba bajo Sancho IV en 1286. Public. por R. Menéndez Pidal, Madrid, 1906, Tomo I- Texto, pp. 480-81.

${ }^{97}$ En el mismo lugar, próximo al rio Pisuerga, en que treinta años antes, su hermano, el caballero Alpidio, "quodam vero die aduenit illi volumtas ut egredetur ad venatum et inueni vestigia aper magnus; et cum suos homines et suos cannes sequendo ipsa vestigia deuenit usque in monten qui erat super ripam fluminis Pisorga. Et conculcantem ipsa vestigia, illuc atque illuc per ipsum montem inuenit unam porcam cum suos filios latantem super unam ecclesiam subtus unum arborem sabuci erat ipsa ecclesia fundata latus unam penne (sic). Et subtus ipsa penna inuenit aliam ecclesia cum tres titulos vidente vero ipsum locum dimisit venatum et cum suos homines cucurrit et retulit in omnia quecumque viditb, en J. PÉreZ DE URBeL, Historia del condado de Castilla Madrid, CSIC, 1945, tomo III, doc. 14.

98 «Et otro dia caualgo alli un cauallo, et fue correr mont; et fallo un puerco dentro en una grand montanna. El puerco acogiose a una cueua do solie maner; pero non se assessego en essa cueua, et fuxo pora una hermita que auie y en essa montanna, et entro, et metiose tras el altar. Et aquella hermita estaua toda cubierta de una yedra, assi que fascas non parescie della ninguna cosa; et uiuien y tres monges muy lazradamientre; et dizien a aquel lugar Sant Pedro. Et el conde non pudo yr de bestia por la montanna tras el puerco, et ouo a descender del cauallo et yr de pie. Et assi como llego, entro por la eglesia et fue all altar alli do yazie el puerco; et quando uio aquel lugar tan onrrado, recelose dell, et non quiso matar el puerco; et dixo assi como en faziendo oracion...», en Primera Crónica General, p. 393.

99 G. ARGAIZ, Soledad lavreada por san Benito y sus hijos, en las iglesias de España y teatro monastico de la provincia de Astvrias, y Cantabria. Madrid 1675, tomo sexto, p. 66. «Lo que todos afirman es, que fundò a san Antolin el Conde Muffazan, que fue vn gran sextor, en aquel tiernpo, en tierra de Asturias. Este, andando a caza por aquella soledad, y siguiendo vn jabali, que auia levantado, escondiòsele en el sitio que està el Monasterio, y reparando en ell le vinieron deseos de levantar aquella Iglesia, poniendo Monges, que alabasen a Dios. Otros dizen mas, que no matò la fiera, sino que alli se le desapareciò, dexando cierta senfal: Y movido con el sucesso edificd el Monasterio, mandandole todo el lugar, con el Beneficio, y con su coto redondo, en la forma, que oy se possee, junto con otros quatro lugares, y sus Beneficios, por donde dizen passò el jabali. Esta seffal, dizen, que fue vna luz, o candela que llevava en la boca, y dexò en llegando a la Cueba donde tenia su guaridas, en P. FERNÁNDEZ DEE PULGAR, ob. cit., Lib. II, p. 10. 
1052 por el rey García Sánchez III de Navarra ${ }^{100}$; o, en fin, del aragonés San Juan de la Peña fundado en 1071 por el rey Sancho Ramírez de Aragón ${ }^{101}$. Por otra parte, el prodigioso milagro de San Antolín no recibe la más mínima alusión en el privilegio de restauración otorgado por el propio protagonista, el rey Sancho III. Y sin embargo, un numeroso grupo de historiadores posteriores, sin la más mínima actitud crítica, han venido difundiendo y aceptando la verosimilitud del relato hasta bien avanzado el siglo XX, como el obispo palentino Rodrigo Sánchez de Arévalo ${ }^{102}$ en el XV; Alonso Fernández de Madrid, arce-

100 «Andaba el rey D. García a caza de la otra parte del río Najerilla, entretenimiento en que se suelen ocupar los reyes; llevaba un azor en la mano, con deseo de que se levantase algún pajaro en qué poder cebarle y entretenerse; levantó una perdiz, y el rey soltó el azor que fuese en seguimiento de ella, y a todo correr del caballo procuraba no perder la vista estas dos aves, las cuales dieron consigo de la otra parte del río Najerilla; viólas que se metieron en una cueva que estaba en pefia tajada; el caballo del rey era bueno y el rio se podía vadear, y engolosinado con la caza, fué siguiendo a los pájaros, y considerando el lugar en donde se habian encovado, apeóse del caballo y procuró quitar todos los estorbos que le podían ser de embarazo, y con estas diligencias y con su gran ánimo forcejeó hasta subir a la cueva, que estaba cavada en la pena viva y tenía la boca estrecha, y así de suyo era oscura, pero entrando el rey en ella, halló tanta claridad como si el sol la diera de lleno en lleno. Con esta luz pudo ver un altar que estaba en la cueva, y sobre él una devota imagen de la gloriosa Reina de los Angeles, con su sagrado Hijo en los brazos. En el mismo altar habían posado el azor y perdiz, y con ser aves tan enemigas, como si no lo fueran estaban entonces en paz y con sosiego, y al pie del altar vió el rey una campana mediana, que hoy día se conserva y se llama de Nuestra Senora... «, en A. DE YePEs, Crónica general de la Orden de San Benito. Madrid, BAE, 1959, tomo III, pp. 80-81.

101 El origen de este monasterio se remonta, según una preciosa leyenda, al siglo VIII, cuando dos nobles hermanos, Voto y Feliz, se quedaron en Zaragoza, como mozárabes, bajo el dominio musulmán. Voto, el mayor, salió un día de caza, llegando hasta un «llano hermosisimo del monte Panno (...) bien digno de ser visto, sobre el monasterio de San Iuan de la Pefia. Alli le salio, a caso, un ciervo de su espesura, y corriendo en su seguimiento, a toda furia, sin reparar en el despefiadero, que está bien vezino, entrambos, ciervo y cavallo, llegaron a un mismo tiempo, al principio de la inmensa cayda que tiene la pefia». Voto pidió ayuda a San Juan Bautista y milagrosamente su caballo «se quedó inmobile en la misma vertiente y buelta, en cuya concavidad está la gran cueva, dexando para muchos siglos los pies y manos estampados en la tierra, por testimonio del milagro, que dio principio a tan insigne monasterion. Después de lo cual, Voto «baxó de su cavallo, y con la espada desnuda, començó a cortar las muchas ramas y malezas, que impedian el camino, de aquella cueva, para baxar a ver la profundidad de aquel despeffadero, ... Llegado, aunque con gran trabajo, al centro de la peffa, descubrio entre lo mas espeso de la gran cueva, una pobre hermita, con su casa mal segura, junto a una fuente, con bien claros vestigios, de que solas fieras venian a bever, a ella. Entrando en su Iglesia, y bien presto discurrio con los ojos, por toda su capacidad y espacio, vio delante el altar, dedicado a san Iuan Baptista, su advogado, el cuerpo difunto de un venerable viejo hermitafion, San Juan de Atares, en J. BRIz MARTiNEz, Historia de la fundación y antigüedades de San Juan de la Peña y de los reyes de Sobrarve, Aragón y Navarra. Zaragoza 1620, lib. I, capit. VIII, pp. 35-39.

102 R. SANCHEZ DE ARÉVALO, «Historiae Hispaniae», Hispaniae illustratae seu rerum urbiumque Hispaniae, Lusitaniae, Aethiopiae et Indiae secriptores varii. Edit. por Andreas Schott. Francfort 1603, tomo I, parte III, capítulo XXV, p. 170.

Actas del 1 Congreso de Historia de la Iglesia y el Mundo Hispánico

Hispania Sacra, 52 (2000) 
diano del Alcor ${ }^{103}$, el jesuíta Juan de Mariana ${ }^{104}$ y el cronista Ambrosio de Morales ${ }^{105}$ en el XVI; el canónigo penitenciario Pedro Fernández del Pulgar ${ }^{106}$, el abad Martín Carrilio ${ }^{107}$, el cardenal César Baronio ${ }^{108}$ y Moret y Alesón ${ }^{109}$ en el XVII; Flórez ${ }^{110}$ y Risco ${ }^{111}$ en el XVIII; o, en fin, Yaben ${ }^{112}$ en la primera mitad del XX.

Es ciertamente posible que el rey Sancho III de Navarra hubiese podido descubrir casualmente la cripta visigoda de San Antolín de Palencia en una jornada venatoria, aunque resta credibilidad al relato el hecho de que en aquellos tiempos fuese corriente aureolar los orígenes o restauraciones de santuarios con narraciones similares. Pero lo que, en opinión de Pérez de Urbel, resulta menos probable es que el altar de la cripta estuviese dedicado a San Antolín, ya que hasta entonces era un mártir desconocido en los santorales visigóticos y mozárabes; su devoción y reliquias fueron importadas por el propio rey Sancho desde Gascứáa $^{113}$.

Toda leyenda con aspiraciones a ser creible necesita poseer cierto grado de verosimilitud; y esta tardía leyenda del suceso de la montería de Sancho III presenta todos los síntomas de no ser una excepción. Si se la despoja de sus ele-

${ }^{103}$ Quien, incluso, introduce en la escena del relato, haciéndole dialogar, a «nuestro glorioso patrón el mártir San Antolín», en A. FERNANDEZ DE MADRm, ob. cit., pp. 63-68. Fecha este suceso entre los affos 1017, en que «estaba esta ciudad desierta y hecha un bosquen y «cerca del año 1020, poco más o menos», en que tuvo lugar la reedificación de la iglesia por Sancho III.

104 J. DE MARIANA, «Historiae de rebus Hispaniae», Hispaniae illustratae..., tomo II, libro VIII, capítulo XIV, p. 454

${ }^{105}$ A. DE MORALES, Los cinco libros postreros de la Coronica General de España. Córdoba 1586, pág. 324.

${ }_{106}$ En este caso lo único novedoso es «una imagen de el Martir San Antonino, que con la apresuracion en seguir el jabali, no avia reparado", siendo del «parecer, que el afio de 1030 fue el milagro de San Antoliny, en P. FERNÁNDEZ DEL PUlGAR, ob. cit., libro II, p. 3. Afirma, además, que en dos af̂́os se reedificó el templo y la ciudad.

${ }^{107}$ M. CARRILLo, Anales cronologicos del mundo. Zaragoza 1634, lib. IV, fol. $294 \mathrm{v}^{\mathrm{b}}$.

108 C. Baronto, Amnales Ecclesiastici. Coloniae Agripinae 1609, tomo 11, columna 111.

109 J. MORET y F. de ALESÓN, Annales del neymo de Navarra. Reprod. facsimil. Bilbao 1969, tomo I, libro XII, capitulo IV, \& VIII, pp. 645-46. Para ambos este suceso milagroso tuvo lugar, «si bien no se halla instrumento, ni memoria antigua, que precisamente sefrale haver sucedido este affo de 1031. son grandes las conjeturas, de que fue en el, o con poquisima diferencian.

110 E. FLOREZ, ob. cit., tomo VIII, p. 32.

III M. Risco, ob. cit., tomo XXXIV, p. 227 y tomo XXXVIII, p. 42.

112 Para quien uel incidente de la caza influyó en la restauración de la iglesia de San Antolín, mas no en la restauración de la diócesis... Al restaurar el templo de San Antolin, no pensó todavía el rey en restaurar la diócesis de Palencia. Este pensamiento le vino despuésn. Y para quien el uincidente de la caza pudo ocurrir el mismo afio 1029, o, lo más tarde, el 1030m, en H. YABEN, ob. cit. pp. 153-55.

113 J. Pérez DE Urbel, Sancho el Mayor de Navarra. Madrid, Institución "Principe de Viana», 1950 , p. 218.

Actas del I Congreso de Historia de la Iglesia y el Mundo Hispánico Hispania Sacra, 52 (2000) 
mentos más legendarios y pretenciosos, quedarán los más históricos: el hecho de la restauración episcopal de Palencia por Sancho III, ciudad que, aunque en esos momentos carecía de la relevancia anterior, contaba en su favor con la importante fuerza de la tradición representada simbólicamente en la cripta visigoda.

Por otra parte, el relato cronístico del metropolitano de Toledo, Rodrigo Jiménez de Rada, carece de fecha explícita, si bien cabe deducirla con cierta aproximación al ubicar temporalmente el hecho narrado en la secuencia cronológica entre el suceso precedente y el subsiguiente. En tal sentido, la restauración de la sede episcopal palentina viene precedida de la narración de la victoria obtenida por Sancho III sobre las fuerzas del rey leonés Bermudo III, consiguiendo «muchos lugares de su reino»; y le sigue la aceptación por parte del rey Bermudo III de la propuesta de sus nobles, de concertar la paz con el rey navarro mediante el matrimonio de su hermana Sancha, "doncella de gran hermosura», con Fernando, hijo segundo del rey Sancho III.

El primer episodio, Ja penetración de las fuerzas de Sancho III al oeste del Pisuerga para, en una primera intención, castigar a los asesinos del infante García que se habían refugiado en el castillo de Monzón, y, seguidamente, anexionar todo el territorio hasta el río Cea, ocupando el lugar homónimo, así como el monasterio de Sahagún, puede fecharse en torno al año 1029114; de hecho, en los primeros meses del affo siguiente los copistas del monasterio saguntino comienzan a calendar las escrituras con el nombre del rey navarro. Pero también cabe ubicarlo a fines de 1031 o principios de 1032, pues en ese tiempo se produjeron nuevos choques entre las fuerzas de Sancho y de Bermudo.

El segundo episodio hay que situarlo a fines del 1032, cuando Sancho III, teniendo que acudir a Gascuña para reclamar sus derechos sobre el condado que acababa de quedar sin herederos directos por la muerte de Sancho Guillermo, ofreció la concertación de una paz al rey Bermudo mediante la alianza matrimonial de Fernando y Sancha.

Por consiguiente, el relato cronístico de la restauración de la sede episcopal palentina, de acuerdo con su ubicación cronológica en la secuencia narrativa de la crónica de Rodrigo Jiménez de Rada, habría que datarlo, como fechas-topes más dilatadas, entre los años 1029 y 1032; y como términos más reducidos, entre los años 1031 y 1032 . Y, en todo caso, la atribución legendaria de la restauración de la diócesis palentina siempre y únicamente se hace recaer sobre el rey navarro Sancho III.

114 Vid sobre el tema de la muerte del infante García a R. MENÉNDez PIDAL, «El "romanz del infant Garcia" y Sancho de Navara antiemperadon, Historia y Epopeya. Madrid 1934, vol. II, pp. 29-98.

Actas del I Congreso de Historia de la Iglesia y el Mundo Hispánico

Hispania Sacra, $52(2000)$ 


\subsection{La restauración documentada}

La documentación diplomática sobre la definitiva restauración del obispado de Palencia es ciertamente abundante; nada menos que seis privilegios y cinco bulas, por citar los más destacados y próximos al acontecimiento, expedidos por los reyes Sancho III el Mayor de Navarra (21 enero 1035), Bermudo III de León (17 febrero 1035), Fernando I de Castilla y León (1045 y 29 diciembre 1059), Alfonso VI (31 marzo 1090) y Alfonso VII (25 enero 1140) $)^{115}$ y por los papas Pascual II (25 marzo 1116), Honorio II (29 noviembre 1125), Inocencio II (24 abril 1143), Alejandro III (18 agosto 1162) y Lucio III (6 agosto 1182) ${ }^{116}$, contienen información sobre dicho hecho. Sin embargo, sólo los cuatro primeros, los expedidos por los reyes Sancho III, Bermudo III y Fernando I, pueden ser considerados como las actas primigenias de la restauración definitiva del obispado palentino. Ahora bien, al no ofrecer ninguno de ellos las garantías de originales auténticos, sino todas las sospechas que suscitan pseudo-originales rehechos y manipulados con posterioridad, sus formas y contenidos son discutibles y discutidos, por lo que las interpretaciones que de ellos se han dado no siempre resultan convergentes. Parece, pues, necesario abordar individualmente los graves problemas críticos que suscitan.

El extenso privilegio del rey navarro, Sancho III el Mayor, se halla escrito en letra minúscula visigótica redonda sobre un gran pergamino de $65 \times 50 \mathrm{cms}$. Se inicia con la invocación simbólica, crismón estilizado, seguida de la explíci-

115 Todos ellos se hallan en el Archivo de la Catedral de Palencia: el de Sancho III en el Arm. III, Leg. I, núm. 2, ha sido íntegramente publicado, entre otros, por A. FERNÁNDEZ DE MADRD, ob. cit., lámina 11 y versión romanceada en pp. 666-69; P. FERNÁNDEZ DEL PULGAR, ob. cit., lib. II, pp. 40-43 y versión romanceada pp. 44-46; y T. ABajo MaRTIN, ob. cit., doc. 2. El de Bermudo III en el Arm. III, Leg. I, núm. 1, publicado, entre otros, por A. FERNÁNDEZ DE MADRID, ob. cit., lámina 10 y versión romanceada en pp. 665-66; P. FERNÁNDEZ DEL PULGAR, ob. cit, lib. II, pp. 35-36 y versión romanceada pp. 36-37; y T. Abajo MarTín, ob. cit., doc. 1. El primero de Femando I en el Am. I, leg. 1, núm. 1, publicado, entre otros, por P. FERNANDEZ DEL PULGAR, ob. cit., lib. II, pp. 79-84 (con muchas erratas a partir del códice de la biblioteca del Marqués de Montealegre); J. M. QuADRADO y F. J. ParcERSA, Recuerdos y bellezas de España. Palencia. Valladolid, Ambito, 1989, pp. 46-48 (edición facsímil); y T. ABajo MaRTtN, $o b$. cit., doc. 4. El segundo de Fernando I en el Amn. III, leg. 1, núm. 5, publicado, entre otros por A. FERNÁNDEZ DE MADRD, ob. cit, lámina 12 y versión romanceada en p. 673; P. FERNÁNDEZ del Pulgar, ob. cit., lib. II, p. 69 y versión romanceada p. 73; J. M. Quadrado y F. J. Parcerisa, ob. cit., p. 48; y T. ABajo MARTín, ob. cit., doc. 9. El de Alfonso VI en el Arm. III, leg. 1, núm. 9, publicado por P. Fernández DEL PULGar, ob. cit., lib. II, pp. 120-25 y versión romanceada pp. 126-29 y T. ABAJO MARTín, ob. cit., doc. 15. Y el de Alfonso VII en el Arm. III, leg. 1, núm. 8, publicado por P. Fernández del Pulgar, ob. cit., lib. II, pp. $182-84$ y T. Abajo Martin, $o b$. cit., doc. 35.

116 Todas ellas también se hallan en el mismo Archivo de la Catedral de Palencia con los siguientes registros: Arm. III, leg. 8, núms. 1, 2, 3,6 y Arm. III, leg. 2, núm. 26; han sido publicadas en su integridad por T. ABajo MARTí, ob. cil., docs. 25, 30, 41, 62 y 93 . 


\section{MAPA 2}

El obispado de Palencia según la restauración de Sancho III de Navarra (1035)

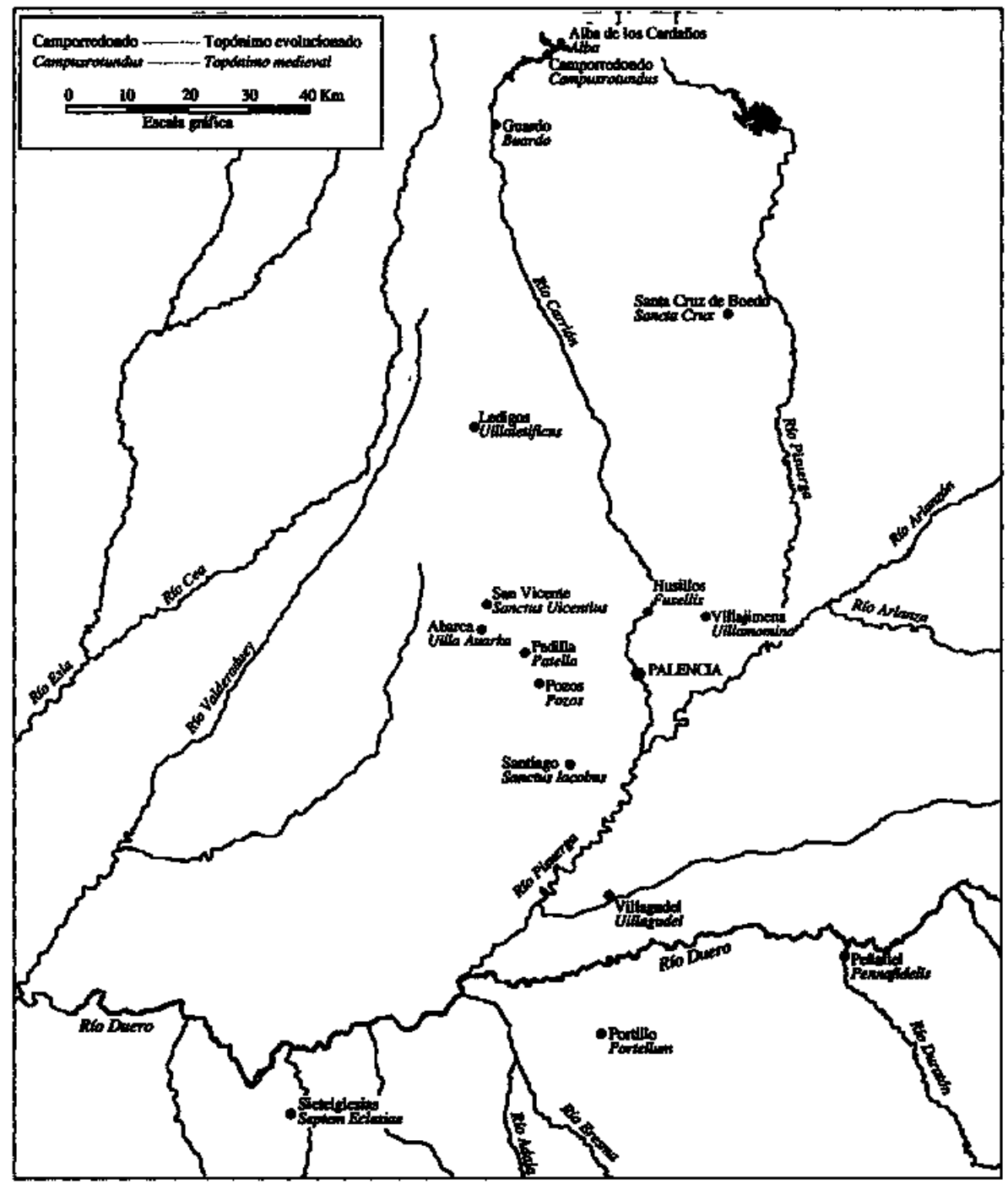

Actas del I Congreso de Historia de la Iglesia y el Mundo Hispánico Hispania Sacra, 52 (2000) 
ta o verbal, bajo la fórmula de la Santísima Trinidad en conjunto. A continuación aparece un elemento en extremo discordante: la primera data cronológica, integrada por el año de la Encarnación, milessimo tricessimo septimo, y la indicción, tercia. Y al carecer de dirección explícita y de salutación, termina el protocolo inicial con la intitulacion, en la que consta el nombre del rey Sancho, simplemente precedido del pronombre ego y acomparado del de la reina Mayor, y haciendo constar el nombre del papa reinante, Benedicto IX, así como la referencia del obispo Poncio, de quien elogia su vida y costumbres.

El cuerpo del documento está constituido por un preámbulo y una exposición muy amplios en los que, respectivamente, justifica los motivos genéricos y particulares que le impulsan a la restauración de la sede palentina, aprobada por la Santa Sede e inducida por el obispo Poncio, a quien encarga su realización. Contiene asimismo una breve notificación universal e impersonal a uniuersus nostrorum conuentus fidelium, tam futurorum quam presentium y una amplia disposición subjetiva, en la que establece lo siguiente: dar a don Ponce y al primer obispo don Bernardo, así como a toda la clerecía palentina, unos genéricos iura et honores episcopatus Palentie; donar a dicha sede y, en concreto a sus obispos y canónigos, una serie de villas, como Sanctam Mariam de Fusellis cum suis uilliis et suis decaniis uel suis terminis antiquis, Sanctum Iacobum cum suis terminis antiquis, Sanctum Uicentium, Sanctam Crucem et Sanctam Mariam de Uilla Auarka, Uillam Iouenales, Patellam, Pozos, Uillamgudel, Uillammominam, cum illarum terminis antiquis, Uillamletificus, Buardo, Campumrotundum, Albam, cum illorum et illarum terminis suis; determinar los límites del obispado, desde los nacimientos de los ríos Cea-Esla y Pisuerga hasta sus respectivas desembocaduras en el río Duero, incluyendo en su parte meridional Peñafiel, Portillo y Siete Iglesias ${ }^{117}$ (Vid. Mapa 2); conceder los excusados y diezmos de las villas que pertenecían al rey, así como omnium iura clericorum districtionis que in sua diocesi sunt, abbatum omnium que in episcopatu Palentie parrochia sunt, además de la decimam partem panis et uini, portaticorum, calumpniarum, pectarum, monetarum, tendarum, molinorum, piscationum et omnis ganadi et aliarum rerum pertenecientes al rey en dicha diócesis; permitir a los prelados cortar lefia y madera de los bosques; $y$ otorgar al obispo los pechos de homicidio y a los pobladores la exención de portazgo, así como de

117 «Hoc est terminum palentine sedis: sicut discurrit alueum Zeie usque diffundit in flumine Duris et de alia parte ubi gignit amne Pisorice et uadit ad Pennafidelis, et ipsum castrum cum terminis suis antiquis, et Portellum cum terminis suis antiquis et Septem Eclesiae cum suis terminis antiquis». Desde luego, esta primera delimitación territorial del recién restaurado obispado de Palencia en nada hace referencia a la supuesta División de Wamba; por el contrario, mantiene el mismo territorio ocupado por la dibcesis palentina en época visigoda, salvo la parte meridional (Segovia, Coca y Buitrago) que, ya entonces, habia sido desgajada para la creación del obispado de Segovia. 
toda autoridad que no sea la episcopal. Termina el cuerpo del documento con las consabidas cláusulas de sanción, alusivas a penas pecuniarias y espirituales.

Por último, el protocolo final o escatocolo posee los elementos de datación y de validación. La datación aparece en términos totalmente distintos de los expresados en la del protocolo inicial; en esta segunda ocasión la data consta de la fecha del mes y del día bajo el sistema romano, XII kalendas ianuarii, así como del año bajo la fórmula de la era hispana, era $M^{a} L X X^{a} V^{a}$, con la mención de los reyes reinantes en Castilla, el propio Sancho III, y en Galicia el leonés Bermudo III. Y en cuanto a la validación, constan las suscripciones de los otorgantes, los reyes citados y su hijo primogénito García en línea, las de los doce confirmantes distribuidas en cuatro columnas (tres infantes, tres obispos, tres condes y tres condesas) y la del notario, el sacerdote Pedro, también en línea; las únicas marcas de validación son los signos del rey y del notario.

Han sido múltiples y diversas las precisiones que acerca de la autenticidad, data y demás contenidos de este documento se han realizado.

Para Alonso Fernández de Madrid el documento en cuestión no levantó la más mínima sospecha de originalidad diplomática ni de autenticidad histórica; no observó en él la evidente discordancia cronológica entre el año de la encarnación del Señor de 1037 o la era hispánica de 1075 y la indicción tercera, 1035, dando por válida la data de «la era de 1075, que fue el año de 1037 del nacimiento del Señor» ${ }^{118}$; y tampoco detectó el anacronismo inadmisible de un documento atribuido al rey Sancho III de Navarra y fechado dos años después de su muerte, acaecida el 18 de octubre de $1035^{119}$.

Joseph de Moret fue el primero en advertir que no se trataba de un documento original, sino de un «trasumpto»; y aunque afirma su contenido cierto y seguro, enseguida observa el anacronismo entre la calendación y el autor, así como la discordancia cronológica entre el año de la Encarnación y la era hispánica con la indicción; califica estos hechos de errores achacables al copista; y concluye que «la escritura del Rey D. Sancho es del anio de Christo 1035», mientras que el día corresponderia al mes de enero y no al de diciembre, adelantándolo once meses por cuanto el copista habría leido equivocadamente XII kalendas februari por XII kalendas januarii ${ }^{120}$.

118 A. FERNÁNDEZ DE MADRID, ob. cit., p. 70.

119 J. PÉREZ DE URBEL, Sancho el Mayor de Navarra, pp. 228-30.

$120 \mathrm{~J}$. de MORET, Investigaciones Historicas de las Antigvedades del Reyno de Navarra. Pamplona 1665, libro III, capítulo III, pp. 606-08 y J. de MORET y F. DE ALESÓN, ob. cit, tomo I, libro XII, capitulo IV, $\S$ XI, p. 666, «el copiador hallando algo gastadas las primeras letras del nombre del mes, y que remataba en uarij, saco inadvertidamente Ianuar $i j$, haviendo de ser Februarij. Y de esta suerte resultaria ser la escritura hecha à 21 de Enero del año de Christo 1035 ».

Actas del I Congreso de Historia de la Iglesia y el Mundo Hispánico

Hispania Sacra, 52 (2000) 
Por su parte, Pedro Fernández del Pulgar, quien, segán parece, no utilizó el ejemplar conservado en el archivo capitular, sino copias existentes en las bibliotecas de los marqueses de Montealegre y del Carpio, califica explícitamente el documento de verídico, por cuanto su legalidad es manifiesta. Detecta la discordancia cronológica entre el año de la Encarnación y la era hispánica con la indicción, si bien la califica de «una errata, de quien hizo la copia», así como el referido anacronismo entre el año de la data y el autor del documento. Afirmando, pues, que «debe corregirse el privilegio, assi en el año de la Encarnacion, como en la Era, por razon de la indicion tercera, y por saberse el año de su muerte, que fue en la Era 1073, que es el año de 1035,... Y segun esto, se debe corregir la Era por la indicion, y no la indicion por la Eras ${ }^{121}$, aunque no admite la corrección del mes propuesta por Moret, por lo que la fecha que propone es «fines de Diziembre de 1035\%.

Opina Hilario Yaben que la acción restauradora de Sancho III de Navarra en Palencia hay que ubicarla entre 1029 y 1035 . En el primer año pudo ocurrir el incidente de la caza, o, «lo más tarde el 1030». Conjetura que el templo de San Antolín pudo estar construido el año 1032. Piensa que cuando Sancho el Mayor publicó su documento, ya estaba realizada la restauración, elegido y consagrado don Bernardo y ya existían culto en la catedral y canónigos adscritos a la misma. $Y$ da como fecha probable del documento, sin que dude de su originalidad ni de su atenticidad, la del 21 de diciembre de $1034^{122}$.

Aunque Pérez de Urbel califica de auténtico, «tal vez algo retocado», el documento de la restauración de Sancho III, también observa que no se trata del original, sino de una copia «en la cual se han introducido algunas interpolaciones». Piensa que algunos elementos, mención de la indicción y del año de la Encarnación, así como otras cláusulas, pudieran obedecer a la presencia de don Poncio, en cuya tierra se usaban hacía tiempo dichas fórmulas. Asimismo detecta las contradicciones en la calendación del documento y acepta la propuesta de Moret de fechar el documento el 21 de enero de $1035^{123}$.

En su Catálogo del archivo de la catedral de Palencia San Martín Payo también detecta los errores de la fecha del documento de Sancho III y, siguiendo las sugerencias de Moret, admite la del 21 de enero de 1035 . En cuanto a su originalidad, piensa que ofrece serios reparos ${ }^{124}$ y que, como ya había referido Luciano

121 P. Fernandez del. Pulgar, ob. cit., lib. II, p. 48.

122 H. YABEN, ob. cit., pp. 153-55.

123 J. PéreZ DE URBEL, Sancho el Mayor de Navarra, pp. 215-17. «Si leyésemos XII de las kalendas de enero habria que fechar la carta el 21 de diciembre de 1034; pero la indicción tercera corresponde a 1035; por lo cual se ha propuesto leer februari en vez de januariin.

124 «No es solamente el error en la fecha y el comenzar con anno incarnationis Domini ..., ni las oscilaciones al escribir el nombre del obispo Poncio y Palencia, sino que en las líneas 11, 13, 19, 21, 
Serrano ${ }^{125}$, se trata de una copia no escrita antes de mediados del siglo XII y por la misma mano que el documento de Fernando I. De todas formas, San Martín Payo, al contrario que Serrano, lo considera sustancialmente auténtico.

Julio González admite la fecha propuesta por Hilario Yaben, 21 de diciembre de 1034, como data del documento de Sancho III, al que considera una falsificación hecha para justificar las aspiraciones arzobispales del prelado de Palencia poco antes de conquistarse Toledo; apunta la posibilidad de que con anterioridad a la restauración de Sancho III el maltrecho edificio visigodo de Palencia ya tuviese culto, puesto que su primitiva titulación a honor del Salvador, según consta en el primer documento original del archivo de la catedral ${ }^{126}$ y en el de Bermudo III, sugiere un origen anterior al siglo XI, en que tal advocación había sido frecuente, para posteriormente, siglo XI, sobreponerse la titulación del mártir oriental, San Antolín, impuesta por el primer obispo palentino, procedente del Pirineo oriental. No obstante, afirma que la restauración de la sede palentina se produjo, de acuerdo con la información de varios diplomas ${ }^{127}$, en los primeros meses del affo 1033, siendo su responsable el obispo don Poncio, quien contó con la ayuda del rey Sancho III de Navarra ${ }^{128}$.

La elevada nómina de inexactitudes y errores contenidos en el diploma de Sancho III le llevan a Emiliano González Díez a declarar «ostentosamente su

$23,24,27,33$ y 35 hay abreviaturas enteramente desusadas en la minúscula visigótica, apareciendo un sin número de palabras con la a carolina. Affádase la abundante historia, un compendio de historia palentina, de que se hace alarde en ambos privilegios, la cláusula recalcada de que Palencia había sido la segunda sede, después de Toledo y la más desconcertante de que el obispo Don Poncio era romano more degens, practicaba la liturgia romana, frases que, sin querer, nos llevan a los días de Gregorio VII, preocupado por la institución de un Metropolitano en Castilla (antes de la reconquista de Toledo) y por la abolición del rito mozárabe), en J. SAN MARTf́N PAYO, "Catálogo del Archivo de la Catedral de Palencia», Publicaciones de la Institución «Tello Téllez de Meneses», 50 (1983) 72.

${ }^{125}$ Quien considera las actas documentales de la restauración de la sede episcopal palentina de sospechosa autenticidad por su redacción y contenido; «más bien las delatan como francamente apócrifas", en L. SERRANO, El obispado de Burgos y Castilla primitiva desde el siglo V al XIII. Madrid 1935. tomo I, p. 231 .

126 Se trata de un privilegio del rey Fernando I y de su mujer, Sancha, fechado el 19 de abril de 1042, por el que conceden inmunidad plena a los bienes y derechos de la sede episcopal palentina. Publ. en T. Abajo Martín, ob. cit., doc. 3.

127 El 30 de junio de 1033 aparece como confimante Pontius, Dei gratia Palentine eclesie episcopus, en un documento de dudosa autenticidad, publ. por J. DEL ÁlAMO, ob. cit., doc. 26 y extractado en J. Pérez de URBet, Sancho el Mayor de Navarra, Apéndice II, doc. LXX. De todas formas, dicho obispo no siempre residió en la ciudad de Palencia, pues el 15 de noviembre de 1033, cuando el rey navarro dominaba el Cea, Poncio era episcopus in Sancta Maria de Fusellos, publ. por M. HerRERo DE LA FuENTE, Colección diplomática del monasterio de Sahagún (857-1230). II (1000-1073). León, Cent. de Est. e Invest. «San Isidoro", 1988, doc. 435.

128 J. GONZALEZ, Siglos de Reconquista, pp. 182-83.

Actas del I Congreso de Historia de la lglesia y el Mundo Hispánico

Hispania Sacra, 52 (2000) 
carácter apócrifo y falsario ${ }^{129}$. Se trata, sin duda, del autor que más cuestiona Ia autenticidad del contenido del referido documento al considerarlo una copia tardía, posiblemente de principios del siglo XII, realizada con una clara intencionalidad de fundamentar «no sólo la posesión pacífica de la ciudad, sino el área jurisdiccional diocesana, retrotrayendo la constitución de la misma a fechas anteriores a la conquista toledana", con lo que los pontífices palentinos tenían en sus manos cun instrumento jurídico de primer orden con valor probatorio para hacer frente a las futuras pretensiones de expansión territorial que se dirijan desde los obispados de León y Burgos y más tarde de Segovia» ${ }^{130}$.

Ibáńez Pérez considera el documento de Sancho III como uno de los más importantes que existen sobre el tema de la restauración de la sede episcopal palentina, «aceptando su contenido, al menos en lo más importante, como legítimos ${ }^{131}$.

Por último, para poner término a esta no exhaustiva nómina de autores, el profesor Martínez Díez también cuestiona críticamente la originalidad del documento de Sancho III, al calificarlo, al igual que a los otros relativos a la restauración de la sede episcopal palentina, de pseudo-originales, ya que no cabe la calificación de copia posterior imitativa, cuyo escriba cometió un error al transcribir la fecha, pues el anacronismo entre las datas del documento y la muerte de su autor se repite con rara coincidencia en dos ocasiones, al consignar el affo de la Encarnación y al expresar la era hispánica. Tal coincidencia en el disparate cronológico pone de relieve, según este historiador del Derecho, el carácter de apócrifo del supuesto diploma de Sancho el Mayor. Además, piensa que también «las cláusulas estilísticas con su ampulosidad disuenan totalmente de los diplomas del Sancho el Mayor» ${ }^{132}$, como la pretendida restauración de muchas sedes episcopales contemplada por el regio otorgante, o la supuesta intervención romana en la reinstauración de la sede palentina. Tales cláusulas opina que

${ }^{129}$ Concreta tales inexactitudes en: «el error evidenciado en la data (...); la utilización de la Indictione, figura desarrollada en la cancilleria pontificia y ajena a la documentación regia; el pertinaz empleo de abreviaturas y signos gráficos alejados del modelo de escritura visigoda; la profunda colonización de expresiones y fórmulas que conectan con la reforma gregoriana de fines del siglo XI; la pretendida prelación de rango de la sede palentina tras la toledana», en E. GonzáLEZ Dízz, "Formación y desarrollo del dominio sefiorial de la iglesia palentina (1035-1351)m, Actas del I Congreso de Historia de Palencia. Tomo II: Fuentes documentales y Edad Media. Palencia, Diputación Provincial, 1987, p. 280.

330 Ibidem, p. 281

131 A. C. IBAÑez Pérez, «La diócesis palentina desde su restauración hasta 1190 , Actas del I Congreso de Historia de Palencia. Tomo II: Fuentes doctumentales, p. 376.

132 G. MARTíNEZ, «Restauración y limites de la diócesis palentinas, Publicaciones de la Institución "Tello Téllez de Meneses», 59 (1988) 358.

Actas del I Congreso de Historia de la Iglesia y el Mundo Hispánico Hispania Sacra, 52 (2000) 
sólo pudieron ser redactadas en el reinado de Alfonso VI. Sin embargo, en cuanto a su historicidad, examinadas las subscripciones y los confirmantes, así como las cláusulas dispositivas del diploma, no encuentra nada que resulte sospechoso, sino rigurosamente verdadero. Por lo que concluye afirmando que el diploma de Sancho III es «con toda evidencia un apócrifo que dio nueva redacción a un viejo documento del año 1033 ó 1034 transcribiendo del mismo únicamente las cláusulas dispositivas con las subscripciones y confirmaciones», no considerando, en cambio, fiable la parte narrativa ${ }^{133}$.

En resumen, expuestas las opiniones que sobre el diploma de la restauración de la sede palentina por Sancho III el Mayor de Navarra han aportado distintos autores, cabe llegar a ciertas conclusiones:

Desde el punto de vista diplomático, el referido documento en la forma en que actualmente se conoce no puede ser considerado más que como falso. No se trata de un original, sino de una copia rehecha con posterioridad a la fecha de su data, bien a fines del siglo Xi o principios del XII, posiblemente en el reinado de Alfonso VI (1065-1109), de un diploma primitivo, hoy perdido, que sirvió de base al escriba para pergeñar el conservado. La falsedad del documento no sólo sería imputable por los indudables anacronismos y disonancias cronológicas de su calendación, ni por sus formalidades estilísticas, ni siquiera por ciertas inexactitudes históricas, sino, sobre todo, más que por la determinación de los límites diocesanos, por la clara intencionalidad de la pretendida prelación de rango de la iglesia de Palencia tras la toledana, motivos que indudablemente fueron los que impulsaron a rehacer buena parte del diploma primitivo.

Ahora bien, esta evidente falsificación diplomática no impide afirmar que gran parte de su contenido histórico es verídico, puesto que otras fuentes atestiguan los acontecimientos en él narrados. La autoría de la restauración de la sede episcopal palentina debe ser atribuida en exclusiva al rey navarro Sancho III el Mayor, único responsable, si bien, para su realización material se valió de la eficaz colaboración de Poncio, monje catalán y obispo de Oviedo; lo que resulta menos verosímil es que para ello contara con la autorización de la Santa Sede. La razón de Sancho III al restaurar la sede palentina bien pudo obedecer a un acto deliberado de agresión política: liberar de la influencia leonesa la llanura que se extiende entre el Pisuerga y el Cea, donde situó sus límites oriental y occidental ${ }^{134}$; pero también pudo obedecer a un acto más tuitivo: poner fin a las

\footnotetext{
133 Ibidem, p. 359.

134 Tesis mantenida por J. Pérez de Urbel, Sancho el Mayor de Novarra, p. 215, o por J. M. QUADRADO y F. J. PARCerisa, ob. cit., p. 46, quienes afirman lo siguiente: «Doloso es decirio, pero tal vez esta resurrección de Palencia, precedida de prodigios y con tan nobles designios aparentemente motivada, inspirosela al rey D. Sancho mas que la piedad la ambicion y la mira de afianzar por medio de una colonización inteligente sus injustas conquistas».
}

Actas del I Congreso de Historia de la Iglesia y el Mundo Hispánico

Hispania Sacra, 52 (2000) 
disputas castellano-leonesas sobre estos territorios, creando una diócesis entre ambos ríos que separara, a modo de cuña, las sedes de León y de Burgos ${ }^{135}$. De lo que no cabe duda es de que esta restauración del episcopado palentino no contó con el beneplácito del obispo legionense, al ser perjudicado por la apreciable disminución de su anterior área de influciencia, como queda implícitamente de manifiesto por su ausencia en la confirmación del documento.

Sobre la fecha de la restauración de la sede episcopal palentina por Sancho III conviene hacer alguna precisión. Es posible aceptar como verosímil la sugerencia de Joseph de Moret sobre la data del documento del rey navarro, 21 de enero de 1035; pero tal fecha no indicaría el inicio de la restauración de la sede palentina, sino más bien el final de un proceso iniciado con anterioridad. En tal día se habría producido la celebración de la asamblea del rey con todos aquellos qui ad illum presulatum canonica censura recurrere debent, comitibus, comitum uicariis et cuiusuis conditionis militibus cunctoque etiam clero, abbatibus, monachis, capellanis, diaconibus, subdiaconibus, religiosis, episcopis ita concionatis; y en ella se habría oficializado ritualmente la restauración de la sede palentina; si bien ésta habría tenido lugar unos cinco años antes, de ser cierto el dato aportado por un documento, ciertamente de dudosa fiabilidad, en que por primera vez aparece Poncio con el titulo de Palentine ecclesie episcopus ${ }^{136}$.

El diploma del rey Bermudo III de León se halla escrito en un pergamino de $30 \times 50 \mathrm{~cm}$, de forma rectangular y en buen estado de conservación; su letra es del tipo cursiva visigótica, de trazado próximo a la redonda ${ }^{137}$. Tipólógicamente por su contenido institucional y por el acto de naturaleza procesal que el documento implica cabe catalogarlo como una donación pro anima, por la que el rey Bermudo III entrega al obispo Poncio, así como a todos los clérigos del obispado, la ciudad de Palencia y les asigna rentas (omne debitum) en Abia, Herrera, Castrojeriz, Villadiego, Amaya, Ibia, Iguña, Astudillo, La Vid y Campóo, alfoces que gravitaban a ambos lados del río Pisuerga. Tal donación la realiza el rey unilateralmente, sin que el beneficiario tenga algún tipo de protagonismo, el 17 de febrero de 1035.

135 Esta tesis, que sitúa al rey navarro en un papel más ponderado y de gran estadista, como garante y protector de los intereses comunes de castellanos y leoneses, y que conecta más fácilmente con el hecho de la ratificación, poco después, de dicha restauración por el rey leonés Bermudo ПL, aunque corrigiendo los límites, es sustentada por J. M. LACARRA, Historia del reino de Navarra en la Edad Media. Pamplona, Caja de Ahorros de Navarra, 1975, pp. 107-08.

136 Se trata de la donación del monasterio de Santa María de las Muelas, realizada por Sancho III en favor del monasterio de Offa el 27 de junio de 1030. Publ. en J. Pérez DE URBeL, Sancho el Mayor de Novarra, Apéndice II, doc. LV.

${ }_{137}$ Muy semejante al tipo de letra empleada en los documentos de Alfonso VI y de dofla Urraca, según L. NúNez CONTRERAS, «Colección diplomática de Vemudo III, rey de León», Historia, Instituciones, Documentos, 4 (1977) 393, nota 25. 
En cuanto a su estructura formularia, el protocolo se inicia con la invocación monogramática, constituida por el crismón constantiniano de tipo caligráfico; carece de la verbal. Sigue la dirección, bajo una larga fórmula que incluye a Dios, la Virgen y a san Antolín, patrono de la catedral palentina, al que se explicita el calificativo de martiris Christi, así como el emplazamiento de su basílica. Continúa con la intitulación bajo la fórmula siguiente: pronombre personal, nombre del rey, fórmula de derecho divino, nombre de la reina y título de ésta. Prosigue, ya dentro de la parte central del documento, con la exposición de los motivos relacionados con el dispositivo y que se concretan en los genéricos de la propia exaltación real y conveniencia a la grandeza del reino y en los más específicos de propiciar la propia salvación eterna. Posteriormente, aparece el dispositivo con la estructura típica de toda donación: el anuncio establecido mediante los verbos offerimos et damus; el alcance jurídico de la donación, manifestado bajo la fórmula libere et absolute, absque ulla contradictione...; el contenido de la donación que incluye la villa de Palencia, sus pertenencias y ciertas rentas ubicadas en las localidades y comarcas antes citadas; la justificación đe la donación bajo la modalidad propter remedium anime nostre seu parentum nostrorum; la finalidad de la donación que se especifica en la restauración de la sede palentina a instancias del obispo Poncio, en cuyo beneficio y de sus sucesores se personaliza la donación; y la reiteración de los motivos justificativos, genéricos y específicos, ya relacionados en la exposición. Termina el cuerpo del documento con la consiguiente sanción, formulada por las cláusulas prohibitivas y penalizadoras de tipo espiritual, condenación eterna, excomunión, y material o pecuniaria, pago de multa en libras.

Se cierra el documento con el escatocolo, compuesto por la data y las suscripciones. La datación se inicia con la fórmula factam y, al carecer del indicativo del lugar, finaliza con la crónica constituida por la expresión del día y mes por la calendación romana y la del año por la era hispánica. Las subscripciones y signos aparecen como los últimos elementos: la subscripción del rey, primero, ocupando línea entera bajo la fórmula de serenissimus princeps; después, las de los confirmantes distribuidas en tres columnas, encabezada la primera por la reina Jimena; intercalados entre las columnas aparecen dos signos del rey Bermudo y, finalmente, la suscripción notarial en sentido vertical.

Al igual que el documento precedente de Sancho III de Navarra sobre la restauración de la sede episcopal palentina, tampoco éste se trata de un original, sino de una copia posterior, puesto que como afirma Núñez Contreras, ni «la disposición del texto, ni el tipo de crismón, ni el de letra usado en su redacción, ni la colocación y factura del signo regio dejan lugar a dudas sobre la originalidad de este documento» ${ }^{138}$. Sin duda, la copia fue realizada en época posterior a

138 Jbídem, p. 393.

Actas del I Congreso de Historia de la Iglesia y el Mundo Hispánico

Hispania Sacra, 52 (2000) 
la muerte del rey leonés, tal vez en la cancillería de Alfonso VI o de la reina doña Urraca. Pero sobre su historicidad, salvo interpolaciones de ciertos aspectos formales, como la cláusula expositiva y otras expresiones que tenian por objeto revestirlo de mayor solemnidad, acorde con su contenido, tampoco parece existir graves inconvenientes en admitirla. Incluso, hay algunos autores, como González Díez $z^{139}$ o Martínez Díez ${ }^{140}$, que, al no observar en él ninguna tacha de falsedad ni desacuerdos con personajes históricos, reputan sin ambages la autenticidad histórica de su parte dispositiva.

¿Cómo interpretar históricamente esta secuencia documental de duración tan corta (del 21 de enero de 1035 al 17 de febrero del mismo afio), perteneciente a dos reyes distintos y referida a un mismo suceso: la restauración de la sede episcopal palentina?

Hay que notar en primer lugar, que no existe una identidad total en el contenido de ambos documentos. El de Bermudo III no puede ser considerado exactamente como un acta de restauración de la sede episcopal palentina; desde luego en él no consta tal decisión ni se determinan límites diocesanos precisos; al contrario, implícitamente se da por realizada dicha restauración, por lo que su acción de donar a la basílica de San Antolín, al obispo Poncio y demás clérigos la ciudad de Palencia, así como los derechos de otros lugares y comarcas, constituye una especie de confirmación sancionadora de la restauración previamente

139 «Mejor juicio nos merece el diploma de Vermudo II calendado el 17-II-1035 que 'prima facie' no ofrece ninguna tacha de falsedad, a pesar de que se nos haya transmitido en una copia; de ahí que en ausencia de alguna observación seria reputamos la autenticidad del mismon, en E. GoNZALEZ DtEZ, ob. cit., p. 281.

i40 «Pero a pesar de que tanto la paleografia del documento como el estilo redaccional nos levan a datar el documento de Vermudo III hacia finales del siglo XI, no por eso nos atrevemos a calificarlo de totalmente falso 0 apócrifo, pues todos los confirmantes que hemos podido comprobar con otros diplomas indubitados o con datos históricos seguros, como la reina Juana, Pedro obispo de Lugo, Servando de León, Sampiro de Astorga, Poncio de Oviedo, el presbítero Pedro Menéndez, los condes Fernando Flaínez, Fernando Muñoz, Fernando Diaz, Munio Alfonso y Gutier Alfonso, el alférez real Nepociano Osóriz, el merino Fáfila Pérez, los confirmantes Asur Díaz y Pelayo Munóz, así como el notario Martino, todos sin excepción resultan sorprendentemente exactos, y no sería posible tal acierto si no se hubieran transcrito de un auténtico original.

Es evidente que la copia imitativa del supuesto diploma de Vermudo III tuvo origen en un privilegio auténtico aunque fuera después estilísticamente adomado y retocado en la copia. Pero la bltima y definitiva pregunta es ésta: ¿estos retoques alcanzaron también a la parte dispositiva o se limitaron a adornos estilísticos?

La respuesta para nosotros es evidente: nada hay de sospechoso ni de manipulación, ni de interpolación en la parte dispositiva del diploma de Vermudo III; su contenido fue fielmente transcrito en la copia imitativa que se nos ha conservado, la cual limitó exclusivamente sus modificaciones a los retoques y adomos estilisticos", en G. MARTtNEZ, Restauración y limites de la diócesis palentina, pp. 356-57. 
MAPA 3

Dotación de Bermudo III a la diócesis de Palencia (1035)

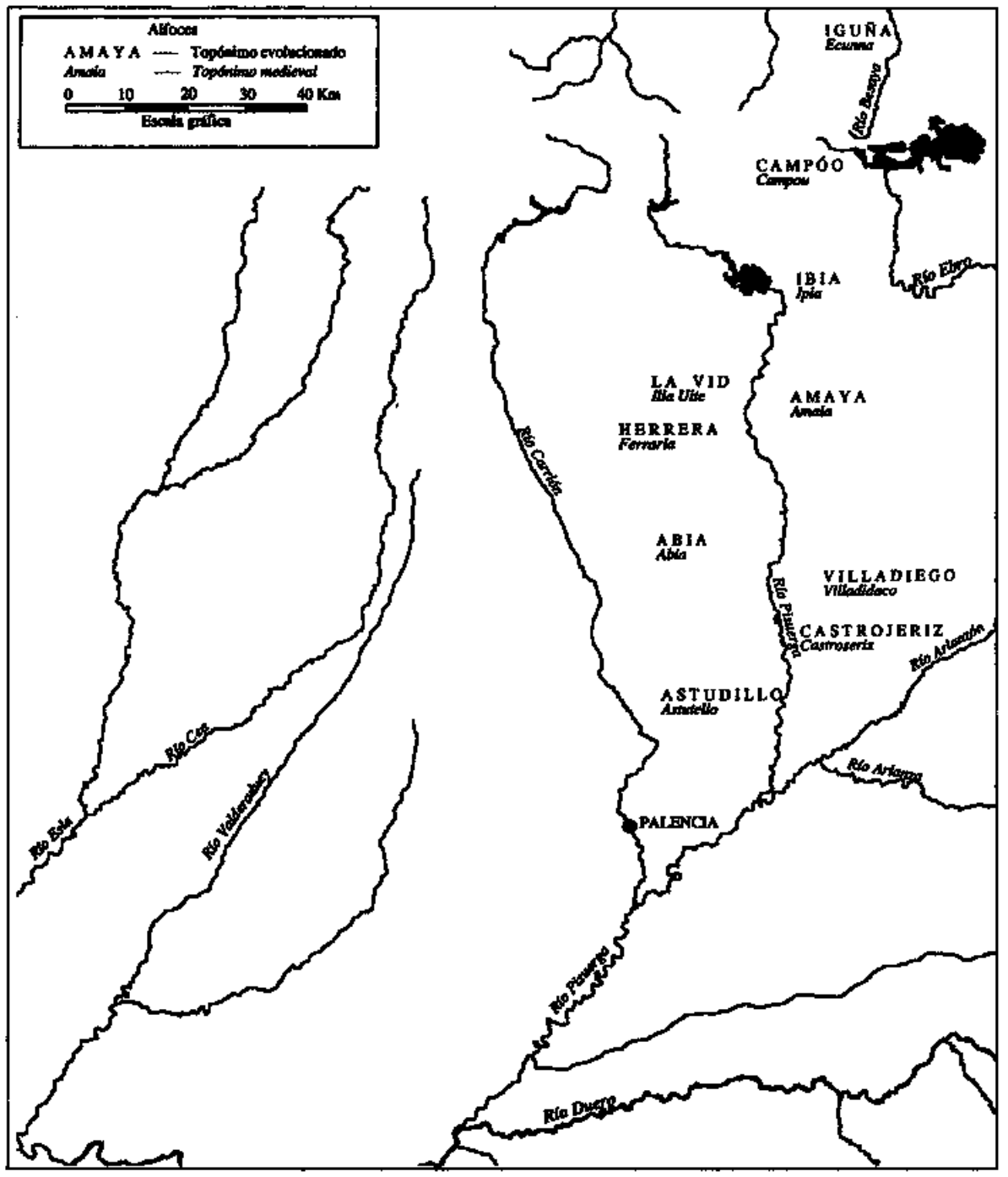

Actas del I Congreso de Historia de la Iglesia y el Murdo Hispánico Hispania Sacra, 52 (2000) 
realizada por Sancho III, aunque su nombre y acción no se mencionen explícitamente.

Conviene constatar en segundo lugar, que algunos de los alfoces (Castrojeriz, Villadiego, Amaya, Ibia, Iguña y Campóo), cuyos derechos se donan al obispo Poncio, se ubican fuera del límite oriental diocesano establecido por Sancho III, en la ribera izquierda del río Pisuerga, y por consiguiente, claramente pertenecientes al condado castellano (Vid. Mapa 3). Sin duda, con ello pretendía ampliar el límite oriental de la diócesis de Palencia, incorporando territorios situados a esta orilla del río Pisuerga.

Hay, por consiguiente, en la acción diplomática de Bermudo III dos hechos aparentemente de diferente alcance: uno de continuidad y confirmación de la acción restauradora de Sancho III y otro de cierta ruptura, al situar el límite oriental de la diócesis palentina más alłá del río Pisuerga, en territorio incuestionablemente castellano, así como la afirmación de la dependencia leonesa de dichos territorios explícitamente manifiesta al ubicar la basílica palentina in suburvio legionense, in uilla uocitata Palencia, in territorio Monteson, prope alueo Karrion.

La razón explicativa no es otra que un cambio brusco en la situación geoestratégica de la zona: en los primeros días del mes de febrero de 1035, un súbito contrataque de Bermudo III al frente de fuerzas leonesas y gallegas consiguió recuperar el territorio situado entre los ríos Cea y Pisuerga, que desde, al menos, el año 1031 estaba en poder del rey navarro, Sancho III. Esta rápida recuperación del territorio que correspondía con el espacio otorgado por el rey navarro al recién restablecido obispado de Palencia, situaba al leonés Bermudo III ante el hecho concreto de la restauración de la sede episcopal palentina. Diversas eran sus posibles alternativas: desmontar lo realizado por su enemigo político, el rey navarro Sancho III, o sancionarlo asumiéndolo total o parcialmente. Y ante esta disyuntiva la intervención del propio agente de la restauración, el obispo Poncio, parece haber sido la responsable de que Bermudo III aceptara la acción restauradora del rey navarro, aunque con una modificación significativa: la inclusión en el espacio diocesano palentino de territorios y lugares que, en contra de lo que expresa el propio documento, nunca habían pertenecido al obispado palentino y sí a la Castilla condal, y la gravitación del obispado palentino hacia la órbita leonesa. Lo que puede interpretarse como una maniobra de hostilidad del rey leonés hacia su rival, Sancho III de Navarra.

Dos son los diplomas pertenecientes al primer rey castellanoleonés, Fernando $I$, que en relación con la restauración de la sede episcopal palentina se conservan en el archivo de la catedral.

El primero por su datación está fechado el año 1045 , se halla escrito con letra carolina en un gran pergamino de $75 \times 50 \mathrm{cms}$. Excepto Quadrado y Parce- 
risa, todos los otros autores que han estudiado este documento lo consideran «una falsificación tan burda y tan ampulosa que no resiste el más somero examen crítico» ${ }^{141}$. En concreto, para San Martín Payo use trata de un documento preparado en la última parte del siglo XI, con el fin de defender la elevación de la diócesis palentina al rango de Metropolitanan, en el tiempo en que el papa Gregorio VII, deseoso de restaurar al metropolitano en Castilla, antes de la conquista de Toledo nombró para tal dignidad al obispo de Palencia ${ }^{142}$.

Más que privilegio real, este documento merece ser catalogado como crónica, compendio o narración histórica en la que se describe las vicisitudes pasadas por la sede episcopal palentina: su etapa visigoda, con sus primeros obispos Murila, Conancio, Ascario, Concordio y Boroaldo; los 330 aftos que pasó in viduitate regimine episcoporum por la irrupción árabe; y principalmente la restauración de dicha sede por Sancho III, rex magnissimus et in omnibus sagacissimus hostes, ex regalibus prosapiis nutritus in Pampilonensis partibus, para cuya empresa contó con la eficaz colaboración del obispo ovetense Poncio, strenuus atque prudens opere, predicator continuus, more Pauli apostoli assiduus, así como del primer obispo palentino electo, Bernardo, calidum in amore ecclesiastico. Inserta pretendidos diálogos entre el rey Sancho III y el obispo Poncio, del mismo modo que un apasionado elogio de los reyes Sancho III y Fernando I, quien termina el documento confirmando y corroborando scriptum privilegii ecclesie Palentie, quod fecit Santius rex, genitor meus, Pontio presuli atque Bernardo, primo pontifici, post restaurationem ipsius episcopii.

El segundo diploma del rey Fernando I, fechado el 29 de diciembre de $1059^{143}$, tampoco se trata de un documento original, aunque, al igual que en el caso de los diplomas de los reyes anteriores, sustancialmente debe considerársele como auténtico. Por su tipo de letra, visigótica redonda, por su presentación formal con expresiones en su redacción extrañas a la diplomática de la época y por su contenido, lleno de anacronismos irreductibles, cabe deducir que se trata de una falsa imitación de un original previo, hoy perdido, redactada entre cincuenta y cien años más tarde de la data documental. Incluso, el profesor Gonzalo Martínez llega a sospechar de cierto grado de dependencia de este diploma con relación al anterior de $1045^{144}$, afirmando que el refactor de este

141 Ibidem, p. 359. Al estar escrito en letra carolina primitiva, fecha la realización de este diploma entre los años 1120 y 1140 , periodo de vigencia de dicho tipo de letra.

142 J. San Martín Payo, ob. cit., pp. 19-20.

143 Difieren de esta fecha, en general por haber equivocado el día de las kalendas (VII por IIII), A. FERNÁNDEZ DE MADRID, ob. cit., lámina 12 y versión romanceada en p. 673; P. FeRNÁNDEZ del PULGAR, ob. cit., lib. II, p. 69 y versión romanceada p. 73; y J. M. QUADRADO y F. J. PARCERISA, ob. cit., p. 48.

144 LLegando a afimar que «encontramos en el diploma fernandino algumas muy peculiares cláusulas como $a b$ eois partibus para designar la Catalufia nativa del obispo Poncio que volvemos a leer

Actas del I Congreso de Historia de la Iglesia y el Mundo Hispánico

Hispania Sacra, 52 (2000) 
espúreo diploma de Fernando I, al igual que el de Sancho III, conocía el diploma de Alfonso $\mathrm{VI}$ otorgado el 31 de marzo de 1090, primer original auténtico relativo a la dotación y límites de la sede palentina, del que tomó algunas cláusulas para utilizarlas en su interpolación con la finalidad no de «falsificar nada sino únicamente revestir de mayor solemnidad y elegancia las disposiciones reales de diplomas auténticos que eran sustituidos por los nuevos pseudo-originales» ${ }^{145}$. Pero salvo estos retoques e interpolaciones en las cláusulas de estilo y es posible que también en alguna noticia histórica, la parte dispositiva del diploma fernandino, así como las subscripciones, no despiertan ninguna sospecha y parece que fueron fielmente respetadas.

En el protocolo de este documento Fernando I hace alusión a la difusión e implantación del Cristianismo en España, entre otros por la predicación del apostoli lacobi et comitum eius ac doctoris gentium, así como de su interrupción en Palencia durante más de trescientos años por la llegada de los agareni. Alude asimismo a que en tiempos del rey Alfonso V los uicini episcopi diuisserunt sibi palentium episcopium per sortem, imputando la restauración de la sede palentina a su padre Sancho III de Navarra, inducido por el obispo ovetense Poncio, ab eois partibus oriumdum. También narra la elección del obispo Bernardo, uir ualde nobilis et religiosus, y la dotación de amplios límites y muchas propiedades a la diócesis recién restaurada. Fue esta generosa dotación la que motivó, ya en el obispado de su sucesor, el obispo Miro, un altercado con los obispos vecinos de Burgos (castellonense) y de León, al haber sido dotada la diócesis palentina en perjuicio de sus respectivas diócesis. $Y$ para poner fin a esta disputa tuvo que intervenir Fernando I, quien se vio en la obligación de dictar una resolución sobre la dotación y configuración territorial del nuevo obispado de Palencia.

Por ella confirma, en primer lugar, al obispo Miro y a sus sucesores de un modo más explícito el dominio sobre la ciudad de Palencia y sus gentes, así como sobre otros derechos y bienes de la diócesis ya donados por su padre, el rey Sancho III. Y en segundo lugar, atiende las quejas de los obispos Alvito de León y Gómez de Burgos sobre la disminución territorial de sus respectivas diócesis con una nueva y más determinada configuración territorial de la de Palencia: Castellone cum terminis suis antiquis, et similiter cum omnibus termi-

con sospechosa exactitud literal en el demencial engendro atribuido a 1045, lo que nos hace sospechar si no una comunidad de origen, sí al menos una relación de dependencia de este segundo respecto de aquél. La citada cláusula ab eois partibus nos resulta tan rebuscada que no nos cabe en la cabeza atribuirla a la chancillería fernandina y sí en cambio aparece como más apropiada del latín de alguno de los monjes borgofones que trajo a Espafia la política religiosa de Alfonso VDs, en G. MARTiNEZ, Restauración y límites de la diócesis palentina, pp. 359-60.

145 Ibidem, p. 360 
MAPA 4

El obispado de Palencia según la delimitación del rey Fernando I (1059)

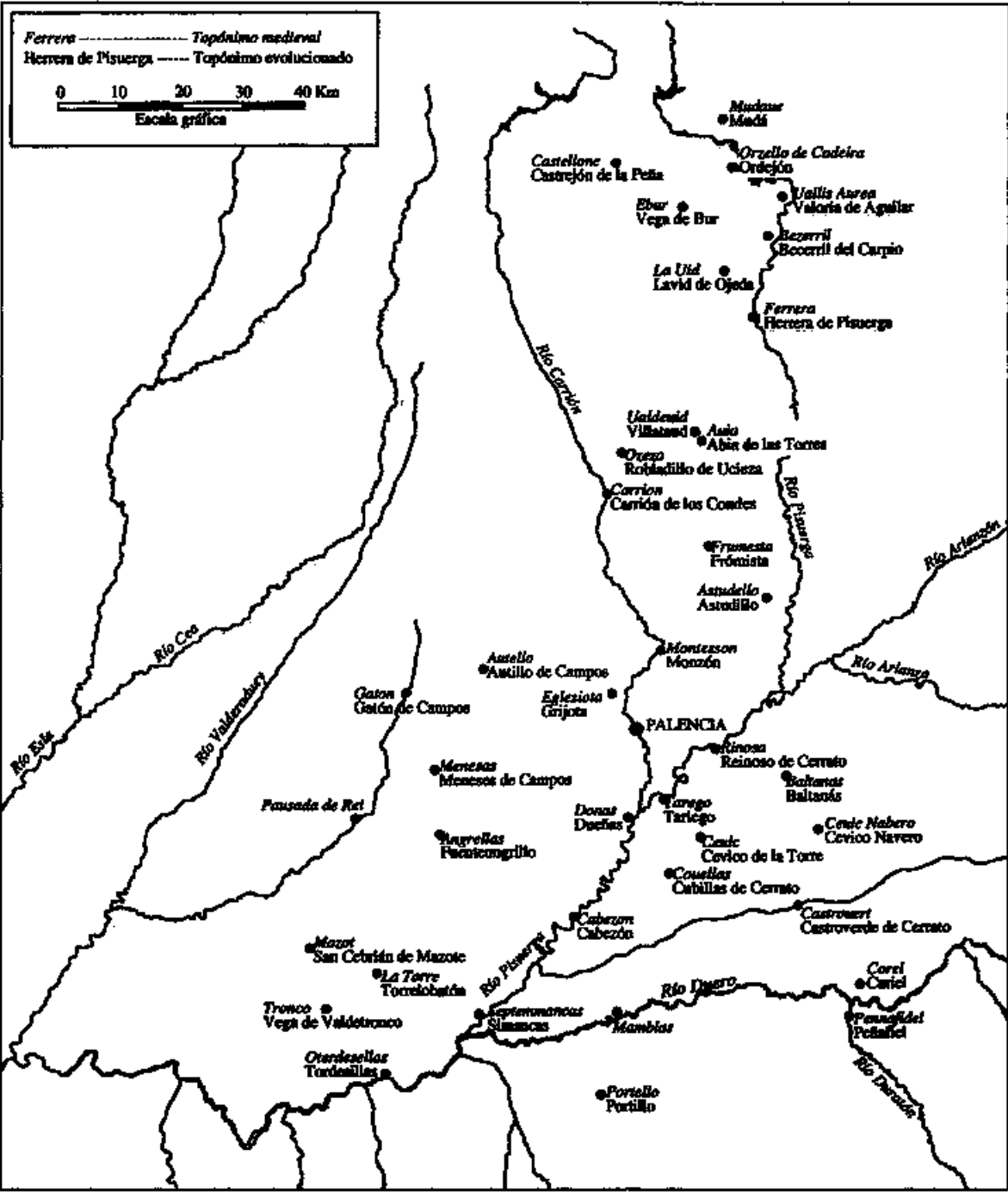

Actas del I Congreso de Historia de la Iglesia y el Mundo Hispánico

Hispania Sacra, 52 (2000) 
nis suis antiquis et alfocibus: Ebur, Mudaue, Orzello de Cadeira, Uallis Aurea, Bezerril, La Uid, Ferrera, Auia, Sancta Maria de Carrion, Frumesta, Ozeza, Astudello, Montesson, Ualdeuid, Rinosa, Baltanas, Ceuic Nabero, Tarego, alio Ceuic, Couellas, Castrouert, Corel, Pennafidel, Mamblas, Cabezon, Portello, Septemmancas, Oterdesellas, Tronco, Mozot, Pausada de Rei, Menesas, Angrellas, La Torre, Gaton, Autello, Eglesiota, Donas. Delimitación y configuración (Vid. Mapa 4) que suponía una cuantiosa disminución del territorio episcopal palentino asignado por los reyes Sancho III y Bermudo III a expensas de los territorios episcopales de León y Burgos respectivamente. El límite oriental volvía a situarse a lo largo del río Pisuerga hasta su encuentro con el río Arlanza y desde ahí hasta Peñafiel, perdiendo los territorios agregados por Bermudo III al otro lado del Pisuerga; el límite occidental sufría también una importante rectificación al abandonar el cauce del río Cea, demarcación fijada por Sancho III, y situarse más hacia el Este, produciéndose un estrechamiento sobre todo en la parte septentrional; mientras que los otros dos confines permanecían prácticamente inalterables. Surgía así la forma de triángulo de isósceles que dibujará el obispado de Palencia en toda la Edad Media, hasta la segregación y creación del obispado de Valladolid en el ańo 1595.

Los dos obispos vecinos, Gómez de Burgos y Alvito de León, parece que aceptaron esta nueva delimitación de la diócesis palentina. De hecho ambas fronteras gozaron de una gran estabilidad: la oriental, lindante con el obispado de Burgos, no volvió a ser motivo de controversias posteriores, permaneciendo su trazado inalterable a lo largo de toda la Edad Media ${ }^{146}$; y la de poniente sólo se vio perturbada por las disputas sobre la jurisdicción episcopal de la villa de Medina de Rioseco que había sido repoblada por Alfonso VII antes de 1139 in territorio de Posada et de uillis episcopatus tui ${ }^{147}$.

Finalizaba así la «fase constituyente» de la restauración del obispado palentino concretada en el establecimiento de un centro rector episcopal en la ciudad de Palencia y en la determinación de un marco territorial dependiente, de forma triangular y genéricamente nucleado en las tierras comprendidas entre los ríos Pisuerga, Carrión, Sequillo y ribera meridional del Duero. Se imponía a partir de entonces, segunda mitad del siglo XI, la concreción más precisa de los lími-

146 De hecho, el 18 de marzo de 1068 en un privilegio atribuido a Sancho II ya se reafirma este mismo limite desde el obispado burgalés: usicut oritur Pisorga cum Petrasnegras cum sua alfoz, et Mutave cum sua alfoz, et Aguilar cum sua alfoz, et Villaescusa et sua alfoz, et similiter Amaya et sua alfoz ex ista parte fluminis, et ex illa sicut labitur in Aslanza, necnon ultra ffluvium de Aslanza ad Villam Flainbista et ad Castriellum de Ovec Didaz et ad Rubiales de Dorio sicut dividitur de Palentino episcopatus, en L. SerrRano, El obispado de Burgos, vol. III, doc. 49.

147 Publ. en T. ABajo MarTtN, ob. cit., doc. 34. 
tes exactos del perímetro territorial de la diócesis, sobre todo en su parte meridional con la aparición de las nuevas diócesis de Zamora, Avila y Segovia, su dependencia metropolitana, su organización administrativa (fundación de la canónica, determinación del número de canónigos, etc.), la configuración de sus respectivas circunscripciones territoriales menores (parroquias, vicarías, arciprestazgos y arcedianatos), la percepción y el reparto del diezmo y la unificación y generalización de la jurisdicción y dependencia episcopal de todas y cada una de las iglesias ubicadas en dicho perímetro y, en especial de las pertenecientes a otros poderes señoriales, comúnmente conocidas como «iglesias propias", lo que daría lugar a todo un semillero de múltiples y prolongados pleitos que se desarrollarán a lo largo de los siglos inmediatos. 